Federal Reserve Bank of Minneapolis

Research Department Staff Report 211

Revised July 1998

\title{
Self-Fulfilling Debt Crises
}

\author{
Harold L. Cole* \\ Federal Reserve Bank of Minneapolis \\ Timothy J. Kehoe* \\ University of Minnesota \\ and Federal Reserve Bank of Minneapolis
}

\begin{abstract}
We characterize the values of government debt and the debt's maturity structure under which financial crises brought on by a loss of confidence in the government can arise within a dynamic, stochastic general equilibrium model. We also characterize the optimal policy response of the government to the threat of such a crisis. We show that when the country's fundamentals place it inside the crisis zone, the government is motivated to reduce its debt and exit the crisis zone because this leads to an economic boom and a reduction in the interest rate on the government's debt. We show that this reduction may be quite gradual if debt is high or the probability of a crisis is low. We also show that, while lengthening the maturity of the debt can shrink the crisis zone, credibility-inducing policies can have perverse effects.
\end{abstract}

*We are grateful to seminar participants at numerous institutions and conferences, V.V. Chari, Ed Green, Patrick Kehoe, Lee Ohanian, Hyun Song Shin, Carlos Vegh, and three anonymous referees. The research of the second author has been supported by a grant from the Air Force Office of Scientific Research, Air Force Materiel Command, USAF, under grant number F49620-94-1-0461. The U.S. government is authorized to reproduce and distribute reprints for government purposes, notwithstanding any copyright notation thereon. The views expressed herein are those of the authors and not necessarily those of the Federal Reserve Bank of Minneapolis, the Federal Reserve System, the Air Force Office of Scientific Research, or the U.S. government. 


\section{Introduction}

Financial crises brought on by a loss of confidence in the government can arise suddenly and threaten countries with huge losses. We analyze the conditions that make these crises possible, and what policy makers should do in the face of this kind of risk. To address these issues, we examine optimal policy in a dynamic, stochastic general equilibrium model in which self-fulfilling crises can arise. The key feature of our model, which allows for selffulfilling crises, is debt rollover. Because of this feature, the liquidity crunch induced by the inability to sell new debt can lead to a self-fulfilling default. We show that, if fundamentals, such as the level of the government's debt, its maturity structure, and the private capital stock, lie within a particular range (the crisis zone), the probability of default is determined by the beliefs of market participants. We show governments are motivated to reduce their debt and exit the crisis zone since doing so leads to an economic boom and a reduction in the interest rate on the government's debt.

The distinguishing feature of this paper is that it examines optimal policy within an environment in which not only can crises occur in the first period, but crises can occur in the future with positive probability. This is important since we show that previously proposed policies that seek to avert a crisis by reacting contemporaneously, such as pegging the interest rate on the government debt or lengthening the maturity of the debt being sold once a crisis has started, are ineffectual in our model. Instead, it is only preemptive policies, which seek to remove the conditions that make future crises possible, that can be effective.

To examine optimal debt policy, we construct a time-consistent equilibrium of our model with a (relatively) easy-to-characterize Markov structure in which a crisis can occur with a positive probability whenever the level and maturity structure of the government's debt and the capital stock are in the crisis zone. We show that within the crisis zone, the country's economic activity is depressed in proportion to the probability that a crisis will take place. We show that the government will find it optimal to reduce its debt so that it exits the crisis zone, since this will lead to investment, output, consumption, and government revenue all rising, while the interest rate on the government debt falls. We also show that, if the probability that the agents in equilibrium assign to a crisis is high, then the government will want to adjust its debt so as to exit the crisis zone immediately, but that as the level of 
the government's debt increases and the probability that the agents assign to a confidence crisis occurring decreases, the number of periods that this transition out of the crisis zone takes can become arbitrarily large.

We consider other policy remedies besides simply lowering the debt. One is lengthening the maturity of the debt in advance of a crisis, which has the intuitive effect of shrinking the crisis zone. For any given debt level, there exists a sufficiently long maturity structure to preclude a future crisis. In addition, we show that such credibility-enhancing policy remedies as increasing the dependence on foreign trade, which work through increasing the costs of default, can be counterproductive. This is because any policy that increases the costs of a crisis without removing the possibility of one occurring need have no effect on the likelihood of a crisis.

We also characterize the types of government that are likely to have nonempty crisis zones. We are surprised to find that a government that cares sufficiently more about private than government consumption or is sufficiently farsighted is guaranteed to have a crisis zone. While these governments have a larger lower bound on debt in their crisis zone, they also have an even larger upper bound.

The specific features of the model are motivated by the crisis in Mexico during 1994-95. In the Mexican crisis, the fear of a government default led to the inability of the government to issue new debt, which in turn seemed about to confirm the fears of a default until the United States intervened with a rescue package. The crisis occurred despite the fact that the Mexican government's fiscal behavior in terms of standard measures, such as its debt/GDP ratio, appears to have been responsible with respect to both its own past behavior and the behavior of many other governments that, at least as yet, have not experienced similar crises. At the time of the crisis, however, the average maturity of Mexico's debt had become very short. When the crisis occurred, the Mexican government found itself unable to sell either dollar-indexed tesobonos or domestically denominated debt, which seems hard to explain on the basis of currency risk, but easy to explain on the basis of default risk. (See Cole and Kehoe (1996) for a fuller discussion of the details of the Mexican crisis.)

The model follows the optimal policy literature in having an infinite horizon and an altruistic government (as in, for example, Chamley (1986)). Hence, neither the policy pre- 
scriptions nor the possibility of a crisis is driven by arcane features of government preferences. Because it is the lack of ability of the government to commit ex-ante to a debt repayment policy that makes crises of confidence possible, we follow Lucas and Stokey (1983) and Chari and Kehoe (1990) in examining the optimal time-consistent policy of the government.

The model in this paper is also related to the literature on how the government's inability to commit to future policy choices can generate multiple equilibria. The first work that makes this point within the context of debt repudiation is by Calvo (1988), who shows in a simple two-period model of sovereign lending that for certain parameter values, two Pareto-ranked equilibria exist. The most closely related paper is by Alesina, Prati, and Tabellini (1990). They show that, even if the government faces a discrete cost of defaulting, its need to roll over its debt can lead to two equilibria. In one equilibrium, a crisis occurs in the first period, and the government repudiates its initial debt. In the other equilibrium, the government is able to roll over its initial debt in the first period and eventually repays it. They show that lengthening the maturity of the government's initial debt from one to two periods can in some cases remove the possibility of the crisis equilibrium. Other papers on self-fulfilling debt crises include Giavazzi and Pagano (1990) and Detragiache (1996). Another related literature is that on self-fulfilling currency crises (see Obstfeld (1994) and Sachs, Tornell, and Velasco (1996)).

This paper differs from most of the literature on debt and currency crises in using a dynamic, stochastic general equilibrium model with an altruistic government rather than using a deterministic model or a model with a reduced form function for the government. While the use of a fully specified dynamic, stochastic general equilibrium model comes at some technical cost, it has at least four advantages: First, it leads to a model that is easy to compare with models used in other areas of modern macroeconomics, such as business cycle theory. Second, it leads to a model whose features are easily matched with the data. Third, the use of a stochastic model allows to analyze the optimal policy response to the threat of a future crisis. Fourth, the use of a fully specified general equilibrium model forces us to be explicit about the assumptions that go into constructing the model and their role in deriving the results. As the discussions in Krugman (1996) and Kehoe (1996) show, dynamic models that rely on reduced form loss functions can produce results that depend, more or 
less arbitrarily, on the specification of within-period timing. The results of the model in this paper are, at least at a qualitative level, robust to this sort of detail

To build up to analyzing the equilibria of interest in our model, we go through several steps. The next section of the paper lays out the basic model. In Section 3, we define a recursive equilibrium that takes into account the strategic incentives of a government that cannot commit to its policy choices and preserves a simple Markov structure for the equilibrium. In Section 4, we characterize an equilibrium in which crises do not occur as a way of illustrating certain basic features of the model. In Section 5, by analyzing an equilibrium in which crises are zero-probability events, we develop a simple condition for when crises are possible. Finally, in Section 6, we characterize the stochastic equilibria of the model in which a crisis can occur with positive probability.

\section{The Basic Model}

There is a single good in each period $t=0,1, \ldots$. This good can be either consumed or saved as capital. Production utilizes capital and, implicitly, inelastically supplied labor. There are three types of people in the model: consumers, international bankers, and the government. We describe each of the types of people in turn.

There is a continuum with measure one of identical, infinitely lived consumers who consume, invest, and pay taxes. The individual's utility function is

$$
E \sum_{t=0}^{\infty} \beta^{t}\left(c_{t}+v\left(g_{t}\right)\right),
$$

where $c_{t}$ is private consumption and $g_{t}$ is government consumption. We assume that $v$ is continuously differentiable, strictly concave, and monotonically increasing. We also assume that $v(0)=-\infty$. The consumer's budget constraint is

$$
c_{t}+k_{t+1} \leq(1-\theta) a_{t} f\left(k_{t}\right)
$$

Here $k_{t}$ is the consumer's individual capital stock; $a_{t}$ is a multiplicative productivity factor that depends on whether or not the government has ever defaulted; $\theta, 0<\theta<1$, is the constant proportional tax on domestic income; and $f$ is a continuously differentiable, concave, and monotonically increasing production function that satisfies $f(0)=0, f^{\prime}(0)=\infty$, and $f^{\prime}(\infty)=0$. The consumer is endowed with $k_{0}$ units of capital in period 0 . 
There is also a continuum with measure one of identical, infinitely lived international bankers. The individual banker is risk neutral and has the utility function

$$
E \sum_{t=0}^{\infty} \beta^{t} x_{t}
$$

where $x_{t}$ is the banker's private consumption. Each banker is endowed with $\bar{x}$ units of the consumption good in each period. Any of the endowment that is not spent on government bonds, along with the proceeds from the previous period's purchase of government debt, is consumed later in the period. When the banker decides how much of the new debt to buy, he faces the budget constraint $q_{t} b_{t+1} \leq \bar{x}$, where $q_{t}$ is the price of one-period government bonds that pay $b_{t+1}$ in period $t+1$ if the government decides to repay its debts and 0 if the government decides not to repay. Subsequently, when the banker decides how much to consume, he faces the constraint

$$
x_{t} \leq \bar{x}+z_{t} b_{t}-q_{t} b_{t+1} \text {. }
$$

We use $z_{t} \in\{0,1\}$ to denote the government's default decision, where $z_{t}=1$ means the government chooses to repay its debts and $z_{t}=0$ means that it chooses to default on its debts. In addition, the bankers face a constraint $b_{t+1} \geq-A$, where $A>0$, that rules out Ponzi schemes, but does not otherwise bind in equilibrium.

It is worth noting that, since the consumers are risk neutral in their own consumption, we can neglect the possibility of their borrowing from, or lending to, the international bankers. Allowing the consumers to be risk averse in their own consumption would complicate the analysis substantially since consumers could be induced by their future income risk to accumulate assets in the form both of capital and, especially, of savings with the international bankers. However, this would not change the essential features of the anlaysis.

There is a single government, which is benevolent in the sense that its objective is to maximize the utility of the consumers. In every period, the government chooses its new borrowing level $B_{t+1}$, whether or not to default on its old debt $z_{t}$, and the level of government consumption $g_{t}$, subject to the budget constraint

$$
g_{t}+z_{t} B_{t} \leq a_{t} \theta f\left(k_{t}\right)+q_{t} B_{t+1}
$$


The government is the only strategic agent in the model, and, when the government makes its decisions, it takes into account these decisions' effects on the price that it will receive for its debt, the level of the aggregate capital stock $K_{t}$, government revenue, and the level of private consumption. In addition, we assume that, if the government defaults on its current debt by setting $z_{t}=0$, then productivity drops from $a_{t}=1$ to $a_{t}=\alpha<1$ from period $t$ onward. We also assume that the government loses access to international borrowing and lending after default. As we shall see, we do not need to impose a borrowing constraint on the government to rule out Ponzi schemes, because, if the government tries to sell too much new debt $B_{t+1}$, its price $q_{t}$ falls to zero.

In each period, the value of an exogenous sunspot variable $\zeta_{t}$ is realized. This variable is independently and uniformly distributed on the interval $[0,1]$. As we shall see, this specification of the sunspot variable allows us to easily construct equilibria in which the probability of a crisis is arbitrary.

The market clearing condition for the government's debt is $b_{t+1}=B_{t+1}$. We assume that the international bankers behave competitively in making their choice of $b_{t+1}$. Because consumers are also competitive, we need to distinguish between the individual decision $k_{t+1}$ and the aggregate value $K_{t+1}$ : consumers should not think that their individual actions affect the aggregate state in the next period, thereby affecting prices or the actions of the government. In equilibrium, because all consumers are identical, $k_{t+1}=K_{t+1}$. We assume, of course, that $k_{0}=K_{0}$ and $b_{0}=B_{0}$.

The timing of actions within each period is the following.

1. The sunspot variable $\zeta_{t}$ is realized, and the aggregate state is $s_{t}=\left(B_{t}, K_{t}, a_{t-1}, \zeta_{t}\right)$.

2. The government, taking the price schedule $q_{t}=q\left(s_{t}, B_{t+1}\right)$ as given, chooses $B_{t+1}$.

3. The international bankers, taking $q_{t}$ as given, choose $b_{t}$.

4. The government chooses whether or not to default, $z_{t}$, and how much to consume, $g_{t}$.

5. The consumers, taking $a_{t}$ as given, choose $c_{t}$ and $k_{t+1}$.

An important feature of our model is the timing of the government's decisions within a period. This timing enables the government to issue new debt before retiring the old debt, while having a maturity of one period on the debt. The need to roll over old debt into new 
is what allows us to have a self-fulfilling crisis. We could also obtain this feature by having longer maturity debt that is only partially rolled over in any period, but this would complicate the analysis. Later we discuss the role of maturity in our results. Variants of the model can be obtained by having consumers make their choices at different points within the period and by delaying the imposition of the default penalty. Although these alternative timing assumptions would change the quantitative results of the model, they would not change its qualitative features.

Two well-known formulations would rationalize our assumption that productivity falls after a default. One story is that a disruption of the country's ability to engage in international trade reduces the value of output. We could assume, for example, that there is a foreign produced intermediate good whose importation is impeded because the foreign creditors can intercept payments made to the producer of this intermediate good. To see how we can incorporate this story into our model, denote by $F(n, k)$ the production function for output as a function the intermediate good $n$ and capital $k$, and by $p$ the price of the intermediate good. Then, if we require that

$$
\begin{aligned}
f(k) & =\max _{n} F(n, k)-p n, \\
\alpha f(k) & =F(0, k),
\end{aligned}
$$

we can simply reinterpret our model as one in which trade disruptions induce a production loss. Among the reasons commonly given for the disruption of trade are confiscation of goods in transit, seizure of trade-related assets, and loss of access to short-term trade credit from intermediaries. (See Obstfeld and Rogoff (1996) for a discussion of these trade sanctions.)

Another story that can rationalize our assumption that productivity falls after a default is that the government's reputation is damaged by its decision to default, which hurts the government's ability to operate, and, consequently, output falls. Defaulting on its debts to the international bankers might, for example, lead the government to lose not only its reputation for repaying its debts, but also for paying the wages of government employees. Hence, the government is no longer able to hire workers, and the level of a valuable government input into private production is reduced. To see this, denote by $F(n, k)$ the production function for 
output as a function the government input $n$ and capital $k$, and assume that $n$ is produced by government workers at wage $w$. For simplicity assume that the optimum $n$ is constant at $\bar{n}$. Then, if we subtract $w \bar{n}$ from government revenue in the government's budget constraint in periods in which no default has previously occurred, and if we require that

$$
\begin{aligned}
f(k) & =F(\bar{n}, k), \\
\alpha f(k) & =F(0, k),
\end{aligned}
$$

we can simply reinterpret our model in which the reputation spillover effect of a default induces a production loss. (See Cole and Kehoe (1997) for more on the reputation spillover story.)

For expositional convenience, we assume that the government loses all access to international borrowing and lending after default. In fact, it is easy to see in the results presented later that the government would not want to borrow again after a default; it would want to lend to smooth post-default government spending. Since allowing for this possibility would change none of our qualitative results but would complicate notation, we ignore it. It is trivial to allow for it.

Finally, we make the simplifying assumption of a constant tax rate because we think that the period over which crises can occur is short compared with that over which tax policy can be changed. Allowing the government to choose the tax rate for the next period in the current period could be incorporated into the model without changing the qualitative conclusions, but at the expense of increasing the model's complexity.

\section{A Recursive Equilibrium}

The government cannot commit itself either to honoring its debt obligations or to following a fixed borrowing and spending path. We therefore define a recursive equilibrium in which there is no commitment and the agents choose their actions sequentially. Within any period, the aggregate state $s=\left(B, K, a_{-1}, \zeta\right)$, the government's policy choices $\left(B^{\prime}, g, z\right)$, the price of bonds $q$, and the choices of individual consumers $\left(c, k^{\prime}\right)$ determine the equilibrium.

To define a recursive equilibrium, we work backward given the timing of actions in each period. The state of an individual agent consists of the aggregate state, any individual 
state variables, and any relevant variables that have already been chosen within the period. Variables are relevant if they affect the agent's maximization problem or the next period's state. The solution to an agent's maximization problem is given by a value function that provides the maximum attainable value of the agent's utility function given his state and policy functions that provide the maximizing choices of the agent's choice variables in the current period given his state. In an equilibrium, agents solve their own problems by correctly predicting what the policies of the other agents will be.

We start the definition of a recursive equilibrium with consumers, because they move last. When an individual consumer acts, he knows the following: his individual capital holding $k$, the aggregate state $s=\left(B, K, a_{-1}, \zeta\right)$, the government's offering of new debt $B^{\prime}$, the price that bankers are willing to pay for this debt $q$, and the government's spending and default decisions, $g$ and $z$, respectively. Since the consumer's choices only depend on the price $q$ through its effect on $g$ and $z$, we define the state of the individual consumer as $\left(k, s, B^{\prime}, g, z\right)$. We denote by $B^{\prime}(s), g\left(s, B^{\prime}, q\right)$, and $z\left(s, B^{\prime}, q\right)$ the government's policy functions, by $q\left(s, B^{\prime}\right)$ the price function, and by $K^{\prime}\left(s, B^{\prime}, g, z\right)$ the function that describes the evolution of the aggregate capital stock, all yet to be defined. The representative consumer's value function is defined by the following functional equation. Subsequently, we provide analytical solutions to this problem and to the other agents' dynamic programming problems.

$$
\begin{aligned}
V_{c}\left(k, s, B^{\prime}, g, z\right)= & \max _{c, k^{\prime}} c+v(g)+\beta E V_{c}\left(k^{\prime}, s^{\prime}, B^{\prime}\left(s^{\prime}\right), g^{\prime}, z^{\prime}\right) \\
& \text { subject to } \\
& c+k^{\prime}-k \leq(1-\theta) a(s, z) f(k) \\
& c, k^{\prime} \geq 0 \\
& s^{\prime}=\left(B^{\prime}, K^{\prime}\left(s, B^{\prime}, g, z\right), a(s, z), \zeta^{\prime}\right) \\
& g^{\prime}=g\left(s^{\prime}, B^{\prime}\left(s^{\prime}\right), q\left(s^{\prime}, B^{\prime}\left(s^{\prime}\right)\right)\right) \\
& z^{\prime}=z\left(s^{\prime}, B^{\prime}\left(s^{\prime}\right), q\left(s^{\prime}, B^{\prime}\left(s^{\prime}\right)\right)\right) .
\end{aligned}
$$

The consumers' policy functions are $c\left(k, s, B^{\prime}, g, z\right)$ and $k^{\prime}\left(k, s, B^{\prime}, g, z\right)$. As we have explained, the production parameter $a$ satisfies $a(s, z)=1$ if $a_{-1}=1$ and $z=1$, that is, if the government has not defaulted in the past and has not defaulted this period. Otherwise, $a(s, z)=\alpha$. 
When an individual banker acts, he knows his individual holdings of government debt $b$, the aggregate state $s$, and the government's offering of new debt $B^{\prime}$. We therefore define the state of an individual banker as $\left(b, s, B^{\prime}\right)$. The representative banker's value function is defined by the functional equation

$$
\begin{aligned}
V_{b}\left(b, s, B^{\prime}\right)= & \max _{b^{\prime}} E\left[\bar{x}+z\left(s, B^{\prime}, q\left(s, B^{\prime}\right)\right) b-q\left(s, B^{\prime}\right) b^{\prime}+\beta V_{b}\left(b^{\prime}, s^{\prime}, B^{\prime}\left(s^{\prime}\right)\right)\right] \\
& \text { subject to } \\
& q\left(s, B^{\prime}\right) b^{\prime} \leq \bar{x} \\
& b^{\prime} \geq-A \\
& s^{\prime}=\left(B^{\prime}, K^{\prime}\left(s, B^{\prime}, g, z\right), a(s, z), \zeta^{\prime}\right) .
\end{aligned}
$$

The banker's policy function is denoted by $b^{\prime}\left(b, s, B^{\prime}\right)$. The policy function is actually a set valued correspondence. Because bankers are assumed to be risk neutral and to behave competitively, they are relatively passive. They purchase the amount of bonds offered by the government as long as the price of these bonds satisfies

$$
q\left(s, B^{\prime}\right)=\beta E z\left(s^{\prime}, B^{\prime}\left(s^{\prime}\right), q\left(s^{\prime}, B^{\prime}\left(s^{\prime}\right)\right)\right) .
$$

In other words, the bankers purchase the bonds as long as the expected gross return on these bonds is $1 / \beta$. In fact, we could simply reinterpret our model as a small open economy in which the pricing function satisfies this relationship, and we could drop consideration of the bankers completely.

The government makes decisions at two points in time. At the beginning of the period, when the government chooses $B^{\prime}$, the government's state is simply the initial state $s$. The government knows how the price that its debt will bring, $q\left(s, B^{\prime}\right)$, depends on this state and on the level of new borrowing. The government also knows what its own optimizing choices $g\left(s, B^{\prime}, q\left(s, B^{\prime}\right)\right)$ and $z\left(s, B^{\prime}, q\left(s, B^{\prime}\right)\right)$ will be later. The government also realizes that it can affect consumption $c$, investment $K^{\prime}$, and the production parameter $a$ through its choices. The government's objective is to maximize the welfare of consumers. The welfare of the bankers does not enter the government's objective. Putting the utility of bankers into the objective function of the government or, equivalently, allowing domestic consumers to hold 
government bonds would change the quantitative, but not the qualitative, features of the model.

The government's value function is defined by the functional equation

$$
\begin{aligned}
V_{g}(s)= & \max _{B^{\prime}} c\left(K, s, B^{\prime}, g, z\right)+v(g)+\beta E V_{g}\left(s^{\prime}\right) \\
& \text { subject to } \\
& g=g\left(s, B^{\prime}, q\left(s, B^{\prime}\right)\right) \\
& z=z\left(s, B^{\prime}, q\left(s, B^{\prime}\right)\right) \\
& s^{\prime}=\left(B^{\prime}, K^{\prime}\left(s, B^{\prime}, g, z\right), a(s, z), \zeta^{\prime}\right) .
\end{aligned}
$$

We denote the government's debt policy by $B^{\prime}(s)$.

Later in the period, the government makes its default choice $z$, which in turn determines the level of productivity $a$ and, through its budget constraint, the level of government spending $g$. Given the government's initial value function, $V_{g}(s)$, we can define the policy functions $g\left(s, B^{\prime}, q\right)$ and $z\left(s, B^{\prime}, q\right)$ as the solutions to the problem

$$
\begin{aligned}
& \max _{g, z} c\left(K, s, B^{\prime}, g, z\right)+v(g)+\beta E V_{g}\left(s^{\prime}\right) \\
& \text { subject to } \\
& g+z B \leq \theta a(s, z) f(K)+q B^{\prime} \\
& z=0 \text { or } z=1 \\
& g \geq 0 \\
& s^{\prime}=\left(B^{\prime}, K^{\prime}\left(s, B^{\prime}, g, z\right), a(s, z), \zeta^{\prime}\right) .
\end{aligned}
$$

Having developed these concepts, we can now define a recursive equilibrium for our model economy.

Definition of an equilibrium. An equilibrium is a list of value functions $V_{c}$ for the representative consumer, $V_{b}$ for the representative banker, and $V_{g}$ for the government; policy functions $c$ and $k^{\prime}$ for the consumer, $b^{\prime}$ for the banker, and $B^{\prime}, g$, and $z$ for the government; a price function $q$; and an equation of motion for the aggregate capital stock $K^{\prime}$ such that the following conditions hold. 
1. Given $B^{\prime}, g$, and $z, V_{c}$ is the value function for the solution to the representative consumer's problem, and $c$ and $k^{\prime}$ are the maximizing choices.

2. Given $B^{\prime}, q$, and $z, V_{b}$ is the value function for the solution to the representative banker's problem, and the value of $B^{\prime}$ chosen by the government solves the problem when $b=B$.

3. Given $q, c, K^{\prime}, g$, and $z, V_{g}$ is the value function for the solution to the government's first problem (7), and $B^{\prime}$ is the maximizing choice. Furthermore, given $c, K^{\prime}, V_{g}$, and $B^{\prime}, g$ and $z$ solve the government's second problem (8).

4. $B^{\prime}(s) \in b^{\prime}\left(B, s, B^{\prime}\right)$.

5. $K^{\prime}\left(s, B^{\prime}, g, z\right)=k^{\prime}\left(K, s, B^{\prime}, g, z\right)$.

While fairly technical in nature, this definition of equilibrium makes clear the nature of the strategic interaction between the government on one side and the consumers and bankers on the other. Although consumers and bankers behave competitively, they understand that the government solves its maximization problem every period. In particular, consumers and bankers understand that under some circumstances, the government will choose to default. Although the government is benevolent, it understands that its actions affect the actions of consumers and, through the price of its bonds, those of bankers.

Our definition of an equilibrium is similar to Chari and Kehoe's (1990, 1993) definition of a sustainable equilibrium and Stokey's (1991) definition of a credible equilibrium. Our definition differs, however, in two respects: First, we have restricted ourselves to a recursivethat is, Markov - equilibrium, and hence the agents' future conditional plans can be derived from their policy functions. Second, we have allowed the private agents to condition their actions within the period on the government's new borrowing level, and hence we do not have to assume that the government sets the prices and the private agents set the quantities.

The goal of this paper is to construct equilibria of the model in which self-fulfilling debt crises can occur with positive probability. We work toward constructing sunspot equilibria for our model economy in three steps: First, we construct an equilibrium in which all the agents simply ignore sunspots. This possibility is always an equilibrium, and it is easy to characterize. Second, we construct an equilibrium in which a crisis can occur, but in which before a crisis occurs, agents assign zero probability to its occurrence. This possibility is also easy to characterize, but whether or not it is an equilibrium depends on the amount 
of government debt. Finally, we construct an equilibrium in which debt crises occur with positive probability. Whether or not this possibility is an equilibrium is easy to determine, but characterizing the equilibrium is more difficult than it is in the first two steps.

In characterizing the equilibrium, we frequently specify the equilibrium outcomes of the state variables, $\left(B_{t}, K_{t}, a_{t-1}, \zeta_{t}\right)$, given initial values $\left(B_{0}, K_{0}, 1, \zeta_{0}\right)$. It is important to notice, however, that to fully specify an equilibrium, we need to specify functions, not realizations. The government, for example, solves its problems (7) and (8) taking the price function for bonds and the policy functions of consumers as given.

It is also important to notice that our notion of a recursive equilibrium is restrictive. If, for example, we were to include the time period in the definition of the state, we could construct equilibria in which crises are only possible in periods whose dates are prime numbers. If we were to allow for nonrecursive equilibria, even stranger possibilities might arise.

\section{No-Crisis Equilibrium With Lending}

In this equilibrium, default on the part of the government occurs either in period 0 or not all, since the bankers will never purchase a level of government debt high enough today that the government will choose to default in the next period. Consequently, the government faces a constraint on new debt, where in every period the expected discounted utility resulting from the government honoring its commitments and setting $z=1$ must be greater than or equal to that resulting from the government defaulting and setting $z=0$. In this equilibrium, if the government, given the current level of its old debt and the amount of new debt it is offering, has no incentive to default, equation (6) implies that the price of new one-period government debt is $\beta$ and that the price is 0 if the government has an incentive to default.

To analyze this type of equilibrium, it is convenient to first characterize the behavior of the consumers and bankers. This is easy to do, since these agents do not behave strategically and their policies are easy to derive given beliefs about the government's choices of $z$ and $z^{\prime}$ (this and next period's default decisions).

The bankers' optimal behavior depends upon their beliefs about $z^{\prime}$. If bankers believe that $z^{\prime}=1$, then they are willing to buy any amount of the government debt up to $\bar{x}$ at price $\beta$. If bankers believe that $z^{\prime}=0$, then they are not willing to buy any debt unless the price 
is 0 (in which case their purchases are irrelevant).

For the consumers as well there are two possible cases, depending on what consumers believe the value of the productivity parameter $a$ will be next period. In one case, the consumers believe that the productivity parameter will be equal to $\alpha$ tomorrow. This belief can arise if the government has already defaulted (either in some prior period or earlier in the current period) or if consumers believe that the government will default next period. In this case, since consumers are risk neutral, it is optimal for them to set the capital stock for next period to a level $k^{d}$ that satisfies

$$
\beta(1-\theta) \alpha f^{\prime}\left(k^{d}\right)=1
$$

and to eat whatever output is left over. In the period in which default occurs, the consumers' level of capital $k$ may differ from $k^{d}$; for example in period 0 it is $K_{0}$. Since consumers' capital stock may take one period to adjust after a default, their consumption is

$$
c^{d}(K)=(1-\theta) \alpha f(K)-k^{d} .
$$

In the other case, the consumers believe that the productivity parameter will be equal to 1 next period because the government has not previously defaulted, and consumers believe that the government will not default next period. In this case, the risk neutrality of the consumers implies that it is optimal for them to set the capital stock for next period to a level $k^{n}$ that satisfies

$$
\beta(1-\theta) f^{\prime}\left(k^{n}\right)=1
$$

and eat whatever is left over,

$$
c^{n}(K)=(1-\theta) f(K)-k^{n} .
$$

Notice that the strict concavity of $f$ implies that $k^{n}>k^{d}$. (For $K_{0}$ sufficiently low, we may need to set $c^{d}\left(K_{0}\right)<0$ or $c^{n}\left(K_{0}\right)<0$; modifying the model to allow consumer borrowing to eliminate this problem would have no significant effect on our results.)

We can now characterize the government's behavior in this equilibrium. For simplicity, we assume that the initial level of the capital stock $K_{0}$ is equal to $k^{n}$. We treat the general case in the appendix. 
We start with the case in which the government has chosen to default. After a default, the government is shut off from the international credit market and, hence, simply consumes its revenues. Therefore, government consumption is given by

$$
g^{d}(K)=\theta \alpha f(K)
$$

In every period thereafter, the capital stock is equal to $k^{d}$, private consumption is equal to $c^{d}\left(k^{d}\right)$, government consumption is $g^{d}\left(k^{d}\right)$, and the government receives a zero price on any new debt that it tries to sell. The payoff to the government if it defaults after it has sold new debt $B^{\prime}$ at price $q$ is given by

$$
V_{g}^{d}\left(s, B^{\prime}, q\right)=c^{d}\left(k^{n}\right)+v\left(\theta \alpha f\left(k^{n}\right)+q B^{\prime}\right)+\beta\left[c^{d}\left(k^{d}\right)+v\left(g^{d}\left(k^{d}\right)\right)\right] /(1-\beta) .
$$

(Remember, however, that this possibility can never occur in equilibrium.) Since $k^{n}>k^{d}$, the government has no incentive to sell additional debt following a default, although it would want to save so that it could smooth spending. As we have explained, we rule out this possibility to simplify the exposition.

Letting $V_{g}^{n}\left(s, B^{\prime}, q\right)$ denote the payoff to the government of not defaulting in state $s=(B, K, 1, \cdot)$ after it has sold new debt $B^{\prime}$ at price $q$ and restricting attention to $K=k^{n}$, we see that

$$
V_{g}^{n}\left(s, B^{\prime}, q\right)=c^{n}\left(k^{n}\right)+v\left(\theta f\left(k^{n}\right)-B+q B^{\prime}\right)+\beta V_{g}\left(s^{\prime}\right)
$$

where $s^{\prime}=\left[B^{\prime}, K^{\prime}\left(s, B^{\prime}, \theta f\left(k^{n}\right)-B+q B^{\prime}, 1\right), 1, \cdot\right]$.

We can now write the constraint on the government's debt that must be satisfied in any equilibrium with positive lending:

$$
V_{g}^{n}\left(s, B^{\prime}, \beta\right) \geq V_{g}^{d}\left(s, B^{\prime}, \beta\right) .
$$

We refer to this constraint as the participation constraint, since it ensures that the government will want to honor the current lending contract with the bankers given that the government is able to sell its new debt.

To characterize the equilibrium in which agents ignore the realizations of the sunspot variable, we need to characterize optimal government behavior with respect to $B^{\prime}$. Fortunately, this is easy. Suppose first that the participation constraint (9) does not bind and that 
$q=\beta$, which it is in any no-crisis equilibrium with positive borrowing. Then given $B_{t}, B_{t+2}$ and $k_{t}, k_{t+1}$, the government chooses $g_{t}, g_{t+1}, B_{t+1}$ to solve the variational problem

$$
\max \beta^{t} v\left(g_{t}\right)+\beta^{t+1} v\left(g_{t+1}\right)
$$

subject to

$$
\begin{aligned}
& g_{t}+B_{t} \leq \theta f\left(k_{t}\right)+\beta B_{t+1} \\
& g_{t+1}+B_{t+1} \leq \theta f\left(k_{t+1}\right)+\beta B_{t+2} \\
& g_{t}, g_{t+1} \geq 0 .
\end{aligned}
$$

It is an immediate consequence of the first-order conditions for this problem that $g_{t}=g_{t+1}$. That is, if the participation constraint does not bind, then it is optimal for the government to maintain a constant level of spending and, hence, of its debt.

We can now characterize equilibrium outcomes when the participation constraint does not bind. In every period, the capital stock is equal to $k^{n}$ and private consumption is equal to $c^{n}\left(k^{n}\right)$. Government consumption is constant at $g^{n}\left(B_{0}\right)=\theta f\left(k^{n}\right)-(1-\beta) B_{0}$, while government debt stays constant at $B_{0}$. The government's payoff from not defaulting is

$$
V_{g}^{n}\left(\left(B_{0}, k^{n}, 1, \cdot\right), B_{0}, \beta\right)=\left[c^{n}\left(k^{n}\right)+v\left(\theta f\left(k^{n}\right)-(1-\beta) B_{0}\right)\right] /(1-\beta) .
$$

If this payoff satisfies the participation constraint, then this is an equilibrium outcome.

When the participation constraint is violated in the proposed equilibrium described above, there are two possibilities: the government may choose to default or it may choose to reduce its new debt in order to reduce its incentive to default and, thus, to satisfy the participation constraint. If the government chooses its new debt level, $B_{1}$, to be different from its initial debt level, $B_{0}$, but then maintains this level thereafter, its payoff from not defaulting is

$$
\begin{aligned}
V_{g}^{n}\left(\left(B_{0}, k^{n}, 1, \cdot\right), B_{1}, \beta\right)= & c^{n}\left(k^{n}\right)+v\left(\theta f\left(k^{n}\right)-B_{0}+\beta B_{1}\right) \\
& +\beta\left[c^{n}\left(k^{n}\right)+v\left(\theta f\left(k^{n}\right)-(1-\beta) B_{1}\right)\right] /(1-\beta) .
\end{aligned}
$$

If $B_{0}=B_{1}$ satisfies the participation constraint, we are in the stationary equilibrium described above. If $B_{0}=B_{1}$ does not satisfy the participation constraint, let $B_{1}\left(B_{0}\right)$ be the largest 
value of $B_{1}$ that satisfies $B_{1} \leq B_{0}$ and the participation constraint, if such a value exists. If no such $B_{1}$ exists, then it is optimal to default.

We denote the upper bound on debt for which default does not occur in equilibrium by $\bar{B}$. In the appendix, we show that there is a unique $B^{s} \leq \bar{B}$ such that $B_{1}=B_{0}=B^{s}$ satisfies the participation constraint with equality, and if $B_{0}<B^{s}$, then $B_{1}=B_{0}$ also satisfies the constraint. Furthermore, if $B_{0}>B^{s}$, then $B_{1}\left(B_{0}\right)<B^{s}$ if it exists.

We define the stationary no-crisis equilibrium as one in which in every period, the capital stock is equal to $k^{n}$, private consumption is equal to $c^{n}\left(k^{n}\right)$, the government sets $z=1$, government consumption is constant at $g^{n}\left(B_{0}\right)=\theta f\left(k^{n}\right)-(1-\beta) B_{0}$, while government debt stays constant at a level less than or equal to $B^{s}$, and the government receives price $\beta$ on its new debt.

We now present a more general characterization of the equilibrium in which all agents ignore the sunspots.

Proposition 1. There exists a continuous and increasing function $\bar{B}(K)$ and a positive debt level $B^{s}$, where $\bar{B}\left(k^{n}\right)>B^{s}$, such that the following outcomes occur.

(i) If $K_{0}=k^{n}$ and $B_{0} \leq B^{s}$, then the economy is in the stationary no-default equilibrium described above in which government debt stays constant at its initial level.

(ii) If $B_{0} \leq \bar{B}\left(K_{0}\right)$, then the economy converges to the stationary no-default continuation equilibrium after at most two periods.

(iii) If $B_{0}>\bar{B}\left(K_{0}\right)$, then the outcome is in the default equilibrium outcome as described above.

Proof. See the appendix.

The upper bound on debt $\bar{B}(K)$ depends upon the current level of the capital stock, which may differ from $k^{n}$ or $k^{d}$ only in period 0 . Two additional aspects of the equilibrium that we have constructed are worth mentioning: One is that, although it is sometimes possible to construct other equilibria, this equilibrium is always an equilibrium. The other is that the discussion in the appendix is complicated by the possibility that $K_{0} \neq k^{n}$, in which case the participation constraint may bind in periods 0 and 1 because it takes one period for capital to adjust to $k^{n}$. 


\section{Zero-Probability Crisis Equilibria and the Crisis Zone}

We now extend the analysis of the previous section to allow for crises to occur, even though agents expect these crises to occur with zero probability. This type of equilibrium is worth studying for two reasons: One is that the conditions under which crises can occur are the same in the zero-probability crisis equilibrium as they are in a sunspot equilibrium, in which the crisis occurs with positive probability. The other is that since the behavior of agents before a crisis occurs in the zero-probability crisis equilibrium follows the same stationary pattern as in the no-crisis equilibrium described in the previous section, these equilibria are much easier to analyze. When crises occur with positive probability, the behavior of agents becomes more complicated.

To see how a self-fulfilling crisis can arise, suppose that the government offers new debt $B^{\prime}$ to international bankers, but, for some reason, these bankers expect the government to default on its old debt $B$. Suppose also that this occurs even though the government satisfies the participation constraint and bankers have not previously attached positive probability to default. Under this conjecture, the price of the new government bonds falls to $q=0$. This crisis is then self-fulfilling if the inability to sell its bonds at a positive price induces the government to default.

To be precise, for a crisis to occur, the government must satisfy a no-lending condition, which says that, if $q=0$, then the government strictly prefers to default:

$$
V_{g}^{d}(s, 0,0)>V_{g}^{n}(s, 0,0)
$$

(Of course, $V_{g}^{d}\left(s, B^{\prime}, 0\right)=V_{g}^{d}(s, 0,0)$ for any $B^{\prime}$, because if $q=0$, the amount of new bonds offered is irrelevant.)

We let $\bar{b}(K)$ be the largest value of $B$ for which the government weakly prefers to repay its debt, even if it cannot sell new bonds at a positive price:

$$
\begin{aligned}
& c^{n}(K)+v(\theta f(K)-B)+\beta\left[c^{n}\left(k^{n}\right)+v\left(\theta f\left(k^{n}\right)\right)\right] /(1-\beta) \geq \\
& c^{d}(K)+v(\theta \alpha f(K))+\beta\left[c^{d}\left(k^{d}\right)+v\left(\theta \alpha f\left(k^{d}\right)\right)\right] /(1-\beta) .
\end{aligned}
$$

It is easy to establish that $d \bar{b}(K) / d k>0$ for $K \in\left[k^{d}, k^{n}\right]$ by simply differentiating both sides 
of (12) and noting that

$$
(1-\theta) f^{\prime}(K)+v^{\prime}(\theta f(K)-\bar{b}(K)) \theta f^{\prime}(K)>(1-\theta) \alpha f^{\prime}(K)+v^{\prime}(\theta \alpha f(K)) \theta \alpha f^{\prime}(K),
$$

since it must be the case that $\theta f(K)-\bar{b}(K)<\theta \alpha f(K)$.

We refer to the range of debt value for which both the participation constraint and the no-lending condition are satisfied as the crisis zone $(\bar{B}(K)>\bar{b}(K))$. To evaluate when we can have a nonempty crisis zone in the stationary equilibrium (when the capital is $k^{n}$ ), we combine the no-lending condition (11) and the participation constraint under a stationary debt policy,

$$
\begin{aligned}
& c^{n}\left(k^{n}\right)+v\left(\theta f\left(k^{n}\right)-(1-\beta) B\right)+\beta\left[c^{n}\left(k^{n}\right)+v\left(\theta f\left(k^{n}\right)-(1-\beta) B\right)\right] /(1-\beta) \geq \\
& c^{d}\left(k^{n}\right)+v\left(\theta \alpha f\left(k^{n}\right)+\beta B\right)+\beta\left[c^{d}\left(k^{d}\right)+v\left(\theta \alpha f\left(k^{d}\right)\right)\right] /(1-\beta),
\end{aligned}
$$

to produce

$$
W_{p}(B) \geq \bar{W}>W_{n l}(B)
$$

where

$$
\begin{aligned}
W_{p}(B)= & v\left(\theta f\left(k^{n}\right)-(1-\beta) B\right)-v\left(\theta \alpha f\left(k^{n}\right)+\beta B\right) \\
& +\beta\left[v\left(\theta f\left(k^{n}\right)-(1-\beta) B\right)-v\left(\theta \alpha f\left(k^{d}\right)\right)\right] /(1-\beta)
\end{aligned}
$$

is the net social benefit in terms of government spending of not defaulting if the government can roll over its debt,

$$
\bar{W}=c^{d}\left(k^{n}\right)-c^{n}\left(k^{n}\right)+\beta\left[c^{d}\left(k^{d}\right)-c^{n}\left(k^{n}\right)\right] /(1-\beta)
$$

is the net social cost in terms of consumption of not defaulting, and

$$
\begin{aligned}
W_{n l}(B)= & v\left(\theta f\left(k^{n}\right)-B\right)-v\left(\theta \alpha f\left(k^{n}\right)\right) \\
& +\beta\left[v\left(\theta f\left(k^{n}\right)\right)-v\left(\theta \alpha f\left(k^{d}\right)\right)\right] /(1-\beta)
\end{aligned}
$$

is the net social benefit in terms of government spending of not defaulting if the government cannot roll over its debt. 
Figure 1 depicts the general situation: $W_{p}(0)=W_{n l}(0)>0, W_{p}^{\prime}(B)<0, W_{n l}^{\prime}(B)<$ $0, W_{p}^{\prime}(0)<W_{n l}^{\prime}(0)$, but $W_{n l}(B)$ tends to $-\infty$ as $B$ tends to $\theta f\left(k^{n}\right)$, while $W_{p}(B)$ tends to $-\infty$ as $B$ tends to $\theta f\left(k^{n}\right) /(1-\beta)>\theta f\left(k^{n}\right)$. Therefore, if the social cost of default in terms of private consumption $\bar{W}$ is sufficiently large, then there is a nonempty interval of stationary levels of government debt $\bar{b}\left(k^{n}\right)<B \leq B^{s}$ for which zero-probability crises are possible, where $B^{s}$, the maximum stationary debt level, is simply the level of debt for which condition (13) holds as an equality.

To characterize situations in which there is a nonempty crisis zone, we parameterize the government's utility function by defining $v(g)=\gamma w(g)$, where $\gamma>0$ determines the preference for government spending and $w$ satisfies the same properties as $v$. (That is, it is a continuous differentiable, monotonically increasing, strictly concave function, with $w(0)=-\infty$.)

Proposition 2. For positive $\gamma$ sufficiently close to 0 or for $\beta<1$ but sufficiently close to 1, there is a nonempty interval of levels of government debt $B, \bar{b}\left(k^{n}\right)<B \leq B^{s}$, for which zero-probability crises are possible.

Proof. See the appendix.

Notice that since changes in $\gamma$ have no effect on consumer behavior, we can interpret changes in $\gamma$ as applying solely to the government's preferences. Notice also that we have shown that, for appropriate $\beta$ and $\gamma$, the crisis zone includes a segment in which the stationary participation constraint does not bind. There is a simple intuition for the first part of this result. If the utility function puts sufficient weight on private consumption, then the high cost of default on consumption makes it possible for the government to satisfy the participation constraint with a relatively high level of debt. Such a high level of debt makes a crisis possible if the government cannot roll over its debt. One interpretation of this result is that governments that care more about private consumption than public consumption have a wider crisis zone. In Figure 1, increasing $\gamma$ shifts down $\bar{W} / \gamma$ while leaving $W_{p}(B) / \gamma$ and $W_{n l}(B) / \gamma$ fixed.

Since causality runs from expectations to interest rates in our model, Calvo's (1988) prescription that the government peg the interest rate simply results in a refusal of the private 
agents to buy government debt. For example, even if the government pegs the price of its debt at $\beta$, the optimal response of the bankers is to buy zero of it if they believe that $z^{\prime}=0$. This result is consistent with the Mexican government's inability to issue new debt at prices above its auctions' reservation price.

\section{A. The Price of Credibility}

Here we reconsider the standard notion that an increase in credibility is good for a government. To do so, consider a country that has raised the credibility of its commitment to repay its debts by increasing the cost of defaulting on its debt through, say, increasing its dependence on foreign trade. In our model, we can think of this as lowering $\alpha$. Raising the cost of defaulting does indeed increase the level of debt that can be sustained if a crisis does not occur, $\bar{B}\left(k^{n}\right)$. It also raises the level of debt at which a crisis is possible, $\bar{b}\left(k^{n}\right)$. It does not remove the possibility of a crisis occurring however, since the gap between $\bar{b}\left(k^{n}\right)$ and $\bar{B}\left(k^{n}\right)$ need not be removed. Hence, if this country's debt places it within the new crisis zone, the consequences of the acquisition of some additional credibility can be to make the effects of a crisis much worse. In fact, as the following proposition makes clear, a sufficiently large cost of default ensures the existence of a crisis zone.

Proposition 3. For $K=k^{n}$ and positive $\alpha$ sufficiently close to 0 , there is a nonempty interval of levels of government debt $B, \bar{b}\left(k^{n}\right)<B \leq B^{s}$, for which zero-probability crises are possible.

Proof. See the appendix.

\section{B. The Role of the Maturity Structure}

We can easily show that by lengthening the maturity structure of the debt, the government can increase $\bar{b}\left(k^{n}\right)$ and, for a long enough maturity structure, completely eliminate the possibility of crises, at least after the first period.

Suppose that the government converts a stationary quantity $B$ of one-period bonds coming due into equal quantities $B_{N}$ of bonds of maturity $1,2, \ldots, N$. Henceforth, the government redeems $B_{N}$ bonds every period and sells $B_{N} N$-period bonds. If there is no possibility of 
a crisis, the price of these bonds is $\beta^{N}$. Maintaining a constant level of government spending, we are therefore able to derive the relation

$$
B_{N}=\frac{1-\beta}{1-\beta^{N}} B
$$

Proposition 4. Consider an economy with one-period bonds in which a zero-probability crisis equilibrium exists for debt levels in the interval $\bar{b}\left(k^{n}\right)<B \leq B^{s}$. For any level of debt $B$ in this interval there exists a maturity of the debt, $N^{\prime}$, sufficiently long so that no crises are possible for any maturity $N \geq N^{\prime}$.

Proof. See the appendix.

The intuition for this result is easy. As the maturity of the debt gets longer, the amount that the government needs to borrow every period get smaller. This decreases the government's incentive to default, whether or not it can roll over its debt. Furthermore, that international bankers refuse to make new loans to the government has less and less impact on the government payoff, and consequently the payoff from not defaulting if the government can roll over the debt converges to that if it cannot. Notice, however, that it is the maturity structure of the prevailing debt, and not that of the debt being issued, that determines whether or not a crisis is possible. Hence, if there is enough debt coming due to allow for a crisis, then contrary to the suggestion of Alesina, Prati, and Tabellini (1990), the maturity structure of new debt being issued is irrelevant to the possibility of a crisis today, although it may remove the possibility of a crisis in the future.

There is an important caveat to the maturity result: it is easy for the government to increase the maturity of its debt in this model because there is no cost to doing so. In a more general framework, there may be significant costs. One well-known example of such a cost arises from a worsening of the time-consistent problem associated with setting the inflation tax. (See Calvo and Guidotti $(1990,1992)$ and Missale and Blanchard (1994) for more on models with this cost.) Notice, however, that in the case of Mexico, where tesobonos were dollar-indexed, this time-consistency problem was not present. 


\section{Sunspots and Self-Fulfilling Crises}

We now consider equilibria in which crises can occur with a positive probability $\pi$ depending on realizations of the sunspot variable. Specifically, if $\zeta \leq \pi$ and $B$ is greater than the crucial level $\bar{b}(K)$ determined by the no-lending condition, then international bankers predict that the government will default on its debt. Bankers are therefore not willing to pay a positive price for the new debt offered and thus provoke a crisis. If, however, $\zeta>\pi$, then international bankers predict that the government will repay its debt, and they are therefore willing to roll over the debt and thus allow the government to honor its commitments. If $B$ is less than or equal to the crucial level $\bar{b}(K)$, however, then no crises can occur, no matter what the realization of $\zeta$ : since bankers know that the government will repay its debt whether or not it is able to sell new debt, bankers purchase the new debt. Because $\zeta$ is uniformly distributed on the unit interval, $\pi$ is both the crucial value of $\zeta$, and the probability that $\zeta \leq \pi$. If $\zeta \leq \pi$, a crisis takes place if the debt is above $\bar{b}(K)$ and below the upper bound implied by the participation constraint, which we now denote $\bar{B}(K, \pi)$ since this bound will vary as we vary $\pi$. In the previous section we have analyzed the limiting case where $\pi=0$.

To construct sunspot equilibria for debt levels in the interval $(\bar{b}(K), \bar{B}(K, \pi)]$, we must characterize the optimal behavior of the consumers and bankers. In constructing the no-crisis lending equilibrium, we have already characterized optimal behavior for these agents when they believe that the government's probability of defaulting next period is 0 or 1 . All that remains is to characterize their behavior when they assign a probability $\pi$ to a crisis occurring in the next period. We can characterize optimal consumer behavior for this case by solving a variational problem. In particular, if default has not occurred in period $t$, the representative consumer chooses $c_{t}, k_{t+1}$ and $c_{t+1}^{n}, c_{t+1}^{d}$, where $c_{t+1}^{n}$ and $c_{t+1}^{d}$ are the choices of consumption in periods $t+1$ contingent on the government not defaulting and defaulting, respectively, to solve

$$
\begin{aligned}
& \max c_{t}+\beta(1-\pi) c_{t+1}^{n}+\beta \pi c_{t+1}^{d} \\
& \text { subject to } \\
& c_{t}+k_{t+1} \leq(1-\theta) f\left(k_{t}\right) \\
& c_{t+1}^{n}+k_{t+2}^{n} \leq(1-\theta) f\left(k_{t+1}\right)
\end{aligned}
$$




$$
\begin{aligned}
& c_{t+1}^{d}+k_{t+2}^{d} \leq(1-\theta) \alpha f\left(k_{t+1}\right) \\
& c_{t}, c_{t+1}^{n}, c_{t+1}^{d}, k_{t+1} \geq 0 .
\end{aligned}
$$

The first-order conditions for this problem imply that investment is stationary at the level $k^{\pi}$ determined by the rule

$$
\beta[(1-\pi)+\pi \alpha](1-\theta) f^{\prime}\left(k^{\pi}\right)=1
$$

and that consumption is

$$
c^{\pi}(k)=(1-\theta) f(k)-k^{\pi} .
$$

(It is here that the risk neutrality of utility in consumption plays its role: if consumers are risk averse, then optimal investment and consumption are not stationary.)

The behavior of bankers who expect default to occur with probability $\pi$ is even easier to describe: bankers purchase whatever amount of bonds the government offers up to $\bar{x}$ as long as

$$
q=\beta(1-\pi)
$$

Before characterizing the government's behavior in this equilibrium, we need to know for what regions of the state space, in particular for which $(B, K)$ values, crises are possible and for what regions default is the only outcome. This then determines the equilibrium price function on government debt and the transition function for the aggregate capital stock as a function of the government's policy choices.

The no-lending condition (11) does not change. No crisis equilibrium is possible if the government weakly prefers to repay its debt, even if it cannot sell new bonds at a positive price. If $B_{0}<\bar{b}\left(k_{0}\right)$, then no crisis is possible in the first period, and if $B_{1}<\bar{b}\left(k^{n}\right)$, then no crisis is possible thereafter in the equilibrium we are constructing.

Explicitly characterizing the participation constraint and the upper bound on debt $\bar{B}(K, \pi)$ is more difficult here because, as we shall see, optimal government policy will not, in general, be stationary in the crisis zone. We can explicitly characterize the upper bound on debt under a stationary debt policy, however, where the capital stock is equal to $k^{\pi}$. Let $B^{s}(\pi)$ be the largest value of $B$ for which 


$$
\begin{aligned}
& {\left[c^{\pi}\left(k^{\pi}\right)+v\left(\theta f\left(k^{\pi}\right)-(1-\hat{\beta}) B\right)\right] /(1-\hat{\beta})} \\
& +\beta \pi\left[c^{d}\left(k^{\pi}\right)+v\left(\theta \alpha f\left(k^{\pi}\right)\right)\right] /(1-\hat{\beta}) \\
& +\beta^{2} \pi\left[c^{d}\left(k^{d}\right)+v\left(\theta \alpha f\left(k^{d}\right)\right)\right] /[(1-\beta)(1-\hat{\beta})] \geq \\
& c^{d}\left(k^{\pi}\right)+v\left(\theta \alpha f\left(k^{\pi}\right)+\hat{\beta} B\right)+\beta\left[c^{d}\left(k^{d}\right)+v\left(\theta \alpha f\left(k^{d}\right)\right)\right] /(1-\beta) .
\end{aligned}
$$

(To simplify notation, we have denoted $\hat{\beta}=\beta(1-\pi)$.) As $\pi$ tends to $0, k^{\pi}$ tends to $k^{n}, c^{\pi}(k)$ tends to $c^{n}(k)$, and this version of the stationary participation constraint (15) tends to that in the equilibrium in which agents ignore sunspots, (13); hence, $B^{s}(0)=B^{s}$.

Proposition 5. If the economy is such that, in the no-crisis equilibrium, the stationary upper bound on debt implied by (13) satisfies $B^{s}>\bar{b}\left(k^{n}\right)$, then (i) for any probability $\pi$, if $K_{0}=k^{n}$, there is a nonempty region of debt levels $\bar{b}\left(k^{n}\right)<B \leq \bar{B}\left(k^{n}, \pi\right)$, and (ii) for $\pi$ sufficiently small and $K_{0}=k^{\pi}$, there is a nonempty region of debt levels $\bar{b}\left(k^{n}\right)<B \leq \bar{B}\left(k^{\pi}, \pi\right)$ for which a crisis can occur.

Proof. See the appendix.

We now construct an equilibrium in which crises occur with positive probability. Suppose, to simplify the discussion, that $K_{0}=k^{\pi}$ and that $B_{0}>\bar{b}\left(k^{n}\right)$. Since $\bar{b}\left(k^{n}\right)>\bar{b}\left(k^{\pi}\right), B_{0}>$ $\bar{b}\left(k^{\pi}\right)$, and the government is faced with the following choices in period 0: default now; plan to run the debt down to $\bar{b}\left(k^{n}\right)$ or less in $T$ periods if no crisis occurs, $T=1,2, \ldots$; or never run the debt down. For each of these choices, we can calculate the expected payoff. The equilibrium is determined by the choice that yields the maximum expected payoff. (Of course, we must show that a maximum expected payoff exists.)

Assuming that $B_{0} \leq B^{s}(\pi)$ so that the participation constraint does not bind, we can solve the government's variational problem to show that the government maintains a constant level of government spending if a crisis does not occur but is possible. If the government plans to run its debt down to $\bar{b}\left(k^{n}\right)$ in $T$ periods, we can use the government's budget constraints to calculate that level of government spending:

$$
g^{T}\left(B_{0}\right)=\theta f\left(k^{\pi}\right)+\frac{\hat{\beta}^{T-1}(1-\hat{\beta}) \beta}{1-\hat{\beta}^{T}} \bar{b}\left(k^{n}\right)-\frac{1-\hat{\beta}}{1-\hat{\beta}^{T}} B_{0} .
$$


(Setting $B_{T}<\bar{b}\left(k^{n}\right)$ cannot be optimal, since it lowers $g^{T}$ and - since, by the definition of $T$, $B_{T-1}>\bar{b}\left(k^{n}\right)$ - does not eliminate the possibility of a crisis before $T$.)

If the government chooses to never run its debt down to $\bar{b}\left(k^{n}\right)$, then government spending is

$$
g^{\infty}\left(B_{0}\right)=\theta f\left(k^{\pi}\right)-(1-\hat{\beta}) B_{0} .
$$

Notice that

$$
\lim _{T \rightarrow \infty} g^{T}\left(B_{0}\right)=g^{\infty}\left(B_{0}\right) .
$$

We can now calculate the expected payoff of running the debt down to $\bar{b}\left(k^{n}\right)$ in $T$ periods:

$$
\begin{aligned}
V_{g}^{T}\left(B_{0}\right)= & \left(1-\hat{\beta}^{T-1}\right)\left[(1-\pi)\left(c^{\pi}\left(k^{\pi}\right)+v\left(g^{T}\left(B_{0}\right)\right)\right)+\pi V_{g}^{d}\right] /(1-\hat{\beta}) \\
& +\hat{\beta}^{T-1}\left[(1-\pi)\left(c^{n}\left(k^{\pi}\right)+v\left(g^{T}\left(B_{0}\right)\right)\right)+\pi V_{g}^{d}\right] \\
& +\hat{\beta}^{T}\left[c^{n}\left(k^{n}\right)+v\left(\theta f\left(k^{n}\right)-(1-\beta) \bar{b}\left(k^{n}\right)\right)\right] /(1-\beta) .
\end{aligned}
$$

where

$$
V_{g}^{d}=c^{d}\left(k^{\pi}\right)+v\left(g^{d}\left(k^{\pi}\right)\right)+\beta\left[c^{d}\left(k^{d}\right)+v\left(g^{d}\left(k^{d}\right)\right)\right] /(1-\beta) .
$$

The formula for $V_{g}^{T}\left(B_{0}\right)$ is easy to understand: In periods $t=0,1, \ldots, T-2, g$ is constant at $g^{T}\left(B_{0}\right), c$ is constant at $c^{\pi}\left(k^{\pi}\right)$, and there is a probability $\pi$ of a crisis. In period $T-1$, however, although there is a probability of a crisis, if this crisis does not occur and the government sets $B_{T}=\bar{b}\left(k^{n}\right)$, then the consumers know that no default can occur in period $T$ and therefore set $k^{\prime}=k^{n}$ and $c=c^{n}\left(k^{\pi}\right)=(1-\theta) f\left(k^{\pi}\right)-k^{n}$. In other words, lowering the debt to the crucial value at which crises cannot occur leads to an investment boom in period $T-1$. In period $T$, consumption and government spending increase, and the equilibrium becomes the stationary no-crisis equilibrium.

It is worth noting that, since consumers are risk neutral, there is no dynamic consistency problem involved in whether or not the consumers believe that the government is going to run its debt down to $\bar{b}\left(k^{n}\right)$ in period $T$ : they set $k^{\prime}=k^{\pi}$ until $B^{\prime}$ is actually equal to $\bar{b}\left(k^{n}\right)$. 
To determine $T$, we merely choose the maximum of

$$
V_{g}^{1}\left(B_{0}\right), V_{g}^{2}\left(B_{0}\right), \ldots, V_{g}^{\infty}\left(B_{0}\right)
$$

Since

$$
\lim _{T \rightarrow \infty} V_{g}^{T}\left(B_{0}\right)=V_{g}^{\infty}\left(B_{0}\right)
$$

where

$$
V_{g}^{\infty}\left(B_{0}\right)=\left[(1-\pi)\left(c^{\pi}\left(k^{\pi}\right)+v\left(g^{\infty}\left(B_{0}\right)\right)\right)+\pi V_{g}^{d}\right] /(1-\hat{\beta})
$$

it is easy to prove that this maximum exists.

More generally, we can show that, if the transition rule for capital is given by

$$
K\left(B^{\prime}\right)= \begin{cases}k^{n} & \text { if } B^{\prime} \leq \bar{b}\left(k^{n}\right) \text { and } a=1 \\ k^{\pi} & \text { if } \bar{b}\left(k^{n}\right)<B^{\prime} \leq \bar{B}\left(k^{\pi}, \pi\right) \text { and } a=1 \\ k^{d} & \text { otherwise }\end{cases}
$$

and the equilibrium pricing function is

$$
q\left(B^{\prime}\right)= \begin{cases}\beta & \text { if } B^{\prime} \leq \bar{b}\left(k^{n}\right) \text { and } z\left(s, B^{\prime}, \beta\right)=1 \\ \hat{\beta} & \text { if } \bar{b}\left(k^{n}\right)<B^{\prime} \leq \bar{B}\left(k^{\pi}, \pi\right) \text { and } z\left(s, B^{\prime}, \hat{\beta}\right)=1 \\ 0 & \text { otherwise }\end{cases}
$$

where $z$ is determined by whether or not the participation constraint is satisfied, then we can prove the following.

Proposition 6. For any $K_{0}$ and $B_{0} \leq B^{s}(\pi)-\theta\left(f\left(K_{0}\right)-f\left(k^{\pi}\right)\right)$, if we denote by $V_{g}^{T}$ the government's payoff when its policy is to lower its debt to $\bar{b}\left(k^{n}\right)$ in $T$ periods while keeping $g$ constant, then a $T \in\{1,2, \ldots, \infty\}$ that maximizes $\left\{V_{g}^{1}\left(B_{0}\right), V_{g}^{2}\left(B_{0}\right), \ldots, V_{g}^{\infty}\left(B_{0}\right)\right\}$ exists, and the following are true. (i) If $K_{0} \geq k^{\pi}$, as $B_{0}$ increases, $T\left(B_{0}\right)$ passes through critical points where it increases by one period. Furthermore, for $\pi$ close enough to 0 , there are necessarily regions of $B_{0} \leq B^{s}(\pi)$ with the full range of possibilities $T\left(B_{0}\right)=1,2, \ldots, \infty$. (ii) If $K_{0}<k^{\pi}$, then the debt may increase in the first period, but afterward follows the same characterization as in (i) since $K_{1}=k^{\pi}$ and $B_{1} \leq B^{s}(\pi)$. The equilibrium behavior of $K$ and $q$ are given by (18) and (19). 
Proof. See the appendix.

If $B_{0}$ is sufficiently high, then the participation constraint binds in period 0 , and, as is the case with the zero-probability crisis equilibrium, the government can either default, or it can set $B_{1}$ below $\bar{B}$, set $g_{0}$ below $g^{T}\left(B_{0}\right)$, and then follow the policy described above starting in the next period.

We are now ready to characterize crisis equilibria taking the participation constraint into account.

Proposition 7. For any probability $\pi>0$ for which there exists a nonempty crisis zone $\bar{b}\left(k^{n}\right)<B \leq \bar{B}\left(k^{\pi}, \pi\right)$, there can exist a crisis equilibrium in which the transition function for capital is given by (18), the price function on government debt is given by (19), and, depending on $B_{0}$, the following outcomes occur.

(i) If $K_{0} \geq k^{n}$ and $B_{0} \leq \bar{b}\left(k^{n}\right)$, then the equilibrium outcome is the same as in the no-crisis equilibrium.

(ii) If $\bar{b}\left(K_{0}\right) \leq B_{0} \leq \bar{B}\left(K_{0}, \pi\right)$, then a crisis occurs with probability $\pi$ in the first period and every subsequent period in which $B>\bar{b}\left(k^{n}\right)$. If $B_{0} \leq B^{s}(\pi)-\theta\left(f\left(K_{0}\right)-f\left(k^{\pi}\right)\right)$, optimal government policy involves running down the debt to $\bar{b}\left(k^{n}\right)$ in $T\left(B_{0}\right)$ periods, while smoothing government expenditures as described in Proposition 6. If $T\left(B_{0}\right)$ is finite and a crisis does not occur $\left(\zeta>\pi\right.$ in the first $T-1$ periods), then following period $T\left(B_{0}\right)$, the equilibrium outcomes correspond to the no-crisis equilibrium. For $B_{0}>B^{s}(\pi)-\theta\left(f\left(K_{0}\right)-f\left(k^{\pi}\right)\right)$, the equilibrium converges to the outcome described in Proposition 6 in at most two periods.

(iii) If $K_{0}<k^{n}$ and $B_{0} \leq \bar{b}\left(K_{0}\right)$, then there is no possibility of a crisis in period 0 , and from period 1 onward, the outcomes correspond to those described in (i) if under the government's optimal policy, $B_{1} \leq \bar{b}\left(k^{n}\right)$ or in (ii) if not.

(iv) If $B_{0}>\bar{B}\left(K_{0}, \pi\right)$, then the only outcome is the default outcome (which is the same here as in the no-crisis equilibrium).

Proof. See the appendix.

This characterization is greatly complicated by the need to consider all possible initial levels of the capital stock. After the first period, however, the capital stock can take on only 
one of three values: $k^{d}, k^{\pi}$, or $k^{n}$. We illustrate our findings for these consistent initial capital stock levels in Figure 2. If we assume that $\bar{b}\left(k^{n}\right)<\bar{B}\left(k^{\pi}, \pi\right)$, the following possibilities for crises are all possible outcomes, depending on $B_{0}$ : Case (i), $K_{0}=k^{n}$, is illustrated by the trajectory starting from $b_{1}$ in Figure 2. Case (ii), $K_{0}=k^{\pi}$, is illustrated by the trajectories starting in the interval $\left[b_{2}, b_{5}\right]$, where these trajectories are drawn under the assumption that a crisis is avoided $(\zeta>\pi)$. The debt levels $b_{2}, b_{3}$, and $b_{4}$ are assumed to be less than $B^{s}(\pi)$; hence, the participation constraint does not bind, and the number of periods until the debt is reduced to $\bar{b}\left(k^{n}\right)$ is increasing in $B_{0}$. For $b_{5}$, the participation constraint requires that the debt drop sharply in the first period, but thereafter works like the other cases, since the debt is now below $B^{s}(\pi)$. Depending on the parameters, in particular on $\pi$, some types of dynamics illustrated in Figure 2 may not exist.

To understand why the government is motivated to run down its debt and thereby deviate from the standard consumption smoothing policy, notice first that, for some initial levels of the debt $B$ larger than $\bar{b}\left(k^{n}\right)$, the government actually receives more when it sells new debt if it tries to sell less debt. To see this, note that even if $B>\bar{b}\left(k^{n}\right)$ but close, then $\hat{\beta} B<\beta \bar{b}\left(k^{n}\right)$. Hence, the government strictly prefers to offer $\bar{b}\left(k^{n}\right)$ units of debt for sale rather than $B$ for all $\bar{b}\left(k^{n}\right)<B<\bar{b}\left(k^{n}\right) /(1-\pi)$. Furthermore, since $\bar{b}\left(k^{n}\right) /(1-\pi) \rightarrow \infty$ as $\pi \rightarrow 1$, the region for which the government receives less and, hence, prefers to run its debt down to $\bar{b}\left(k^{n}\right)$ in one step will come to include all of the region of the crisis zone $\left(\bar{b}\left(k^{n}\right), \bar{B}\left(k^{n}, \pi\right)\right]$ as the probability of a crisis gets large. This is an illustration of how $\pi$ can affect the types of dynamics of the model.

Next, to see that it is not the lower price $\hat{\beta}$ being paid by the bankers for the government's debt that motivates the government to reduce its debt in the crisis zone, consider the case in which $T\left(B_{0}\right)=\infty$. In this case, the government never exits the crisis zone, and its optimal debt policy is to keep the debt constant and thereby smooth government consumption. This outcome arises despite the fact that government discount rate is $\beta$ and the market is paying $\hat{\beta}$ per unit of debt because the government only assigns probability $(1-\pi)$ to the possibility that it has to repay its debt. The government therefore discounts future repayment at rate $\hat{\beta}$ as well. Hence, the government's motivation to run down its debt and thereby deviate from the sort of simple government consumption smoothing policy comes solely from 
the benefits of exiting the crisis zone. It is interesting to note that the government's optimal consumption level is not smooth, since it rises when the debt level hits the threshold $\bar{b}\left(k^{n}\right)$. This level is, however, smooth both during the transition and after the boom, but not equal across these intervals.

\section{A. Domestically Initiated Crises}

The crises that we have examined thus far have been initiated by the self-fulfilling fears of the international bankers and, in this sense, originated within the financial markets. Among its many other types of equilibria, the model also admits an equilibrium with a different kind of crisis, which is initiated by self-fulfilling fears of the domestic investors and, in this sense, originates in the real investment sector. To see this, we need to add an additional sunspot variable $\xi$, which is realized after the government has sold its debt and just before the consumer's decisions. We assume that $\xi$ is also uniformly distributed on $[0,1]$.

Let $\pi_{\zeta}$ denote the probability of a crisis in which $q=0$ whenever $B>\bar{b}(K)$. Now consider an outcome in which consumers' fears lead them to lower their investment level to $k^{\pi_{\zeta}}$. If the government's new borrowing satisfies $B^{\prime}>\bar{b}\left(k^{\pi_{\zeta}}\right)$, then a self-fulfilling crisis next period would be possible given that $K^{\prime}=k^{\pi_{\zeta}}$, since $\bar{b}^{\prime}>0$ and, hence, $\bar{b}\left(k^{\pi_{\zeta}}\right)<\bar{b}\left(k^{n}\right)$. Therefore, consumers' fears that they could be in the crisis zone next period could be selffulfilling, even if $K=k^{n}$ and they were out of the crisis zone today. In this type of equilibrium, the probability of the consumers' fears arising can be quite arbitrary. If we let $\pi_{\xi}$ denote this probability, then any value between zero and one is possible so long as $B^{\prime}>\bar{b}\left(k^{\pi_{\zeta}}\right)$.

Notice that in this new type of crisis, the consumers' fears of a default are fulfilled with probability $\pi_{\zeta}$, and with probability $1-\pi_{\zeta}$, their fears turn out to be groundless. Thus, the equilibrium outcome could potentially exhibit wide swings in investment before a financial crisis that forces the government into default finally arises. Of course, the possibility of such a crisis would give the government an incentive to reduce its debt level to $\bar{b}\left(k^{\pi_{\zeta}}\right)$. Since as $\pi_{\zeta} \rightarrow 1, k^{\pi_{\zeta}} \rightarrow k^{d}$, however, only debt levels at or below $\bar{b}\left(k^{d}\right)$ are sufficiently low so as to ensure that a self-fulfilling crisis is not possible. 


\section{B. Temporary Real Cost of a Default}

Thus far, we have assumed that the exogenous real cost of a default, a fall in $a$ from 1 to $\alpha$, occurs forever. It is interesting to consider what would happen if this penalty were incurred only temporarily. Assume that $a$ falls from 1 to $\alpha$ for only a finite number of periods, after which it returns to 1 until a subsequent default occurs. Assume that this interval is unaffected by whether or not a second default occurs before $a$ returns to 1 . Assume also that the government is allowed to reenter the international credit market before $a$ increases from $\alpha$ to 1 . Then an equilibrium of the model would simply involve restarting after $a$ returns to 1 , in which case $V_{g}^{d}\left(s, B^{\prime}, q\right)$ would be higher, but the qualitative characteristics of the no-crisis and the $\pi$-probability-of-a-crisis equilibrium would be unchanged. If we expand the state space to include the number of past defaults of the government, however, it would be possible to construct sunspot equilibria in which the probability of a crisis depends on the number of past defaults by the government. Such a model would allow one possible interpretation of a reputation for repayment by the government, especially if this probability were increasing in the number of past defaults.

\section{Conclusion}

In this paper, we present a model in which debt crises can take two forms. In one form, fears of a default on the part of the international bankers are self-fulfilling. In the other, the fear of a future default on the part of the government leads domestic investors to reduce the level of real investment, which lowers future output and hence makes possible a subsequent financial crisis, even when a crisis would not have been possible if the level of investment had not fallen. This scenario may, in fact, capture certain important features of the 1994-1995 Mexican crisis since, as is noted in the International Monetary Fund (1995) report, domestic investment fell before the debt crisis occurred.

Our characterization of the conditions under which crises can take place implies several lessons about what policy makers can and cannot do to avoid them. First, standard prescriptions, such as increasing the cost of default to increase credibility, may be a bad idea for the government, since it does not eliminate the possibility of a crisis, but only increases

its severity. Second, since causality runs from expectations to interest rates in our model, 
pegging the interest rate simply results in a refusal by the private agents to buy government debt. Third, if there is enough debt coming due to allow for a crisis, then the maturity structure of new debt being issued is irrelevant to the possibility of a crisis today, although it may remove the possibility of a crisis in the future. Fourth, good governments, in the sense that they are more concerned about private consumption than government consumption or are more patient, are more likely to have a nonempty crisis zone. Overall, our model implies that the only way to avoid debt crises is to avoid the conditions on fundamentals that make them possible: in particular, relatively high levels of debt with a short maturity structure.

In subsequent work, Cole and Kehoe (1996) examine the details of the Mexican crisis. They document one surprising aspect of the Mexican crisis, that, while Mexico's debt/GDP ratio was not high by international standards, it was of very short average maturity by the time of the crisis. In a model calibrated to match the key features of the Mexican economy in 1994, the magnitude and maturity structure of Mexico's debt are consistent with Mexico being in the crisis zone. The model predicts that doubling the average maturity of this debt from roughly 200 days to 400 days, however, would have eliminated the possibility of a crisis. Hence, the model presented here gives a plausible account of why the crisis took place when and where it did.

Recent events in Asia suggest the need to take a broad interpretation of the government's liabilities when evaluating whether it is in the crisis zone. A number of countries, including Korea, Indonesia, Malaysia, and Thailand, appear to have experienced financial problems that are similar to those experienced by Mexico, except that financial crises seem to have originated in the banking systems of these countries. Here, too, the key element allowing these crises to occur is the large amount of short-term liabilities. The threat that this maturity mismatch poses is exacerbated by the decline in the value of the local currency, since the banks' loans are denominated in local currency, while their debts are denominated in dollars. We think that a version of our model that incorporates a private banking system with explicit or implicit government-provided insurance to the foreign lenders could account for these crises as well and could provide a framework within which to evaluate optimal policy toward these crises.

Finally, one additional implication that can be drawn from our work is that since debt 
crises are due to a coordination failure among the private lenders, an international agency that stands ready to act as a lender of last resort would be welfare enhancing. The recent bailout of Mexico and the bailouts that are in progress in Asia suggest that policy makers perceive this need as well. It is important to note, however, that for these sorts of bailouts to be successful, the policy makers must be able to distinguish between confidence crises and crises in which the government would have an incentive to default even if it could sell new debt. Furthermore, reducing the likelihood of a crisis actually leading to a default reduces the cost to a government of being in the crisis zone, and that this will in turn reduce a government's incentive to run its debt down and exit the crisis zone. 


\section{References}

Alesina, Alberto; Prati, Alesandro; and Tabellini, Guido. 1990. "Public Confidence and Debt Management: A Model and a Case Study of Italy," in Public Debt Management: Theory and History, ed. Rudiger Dornbusch and Mario Draghi, Cambridge University Press, Cambridge, 94-118.

Calvo, Guillermo A. 1988. "Servicing the Public Debt: The Role of Expectations," American Economic Review 78(4): 647-661.

Calvo, Guillermo A., and Guidotti, Pablo E. 1990. "Indexation and Maturity of Government Bonds: An Exploratory Model," in Public Debt Management: Theory and History, ed. Rudiger Dornbusch and Mario Draghi, Cambridge University Press, Cambridge, 52-82.

Calvo, Guillermo A., and Guidotti, Pablo E. 1992. "Optimal Maturity of Nominal Government Debt: An Infinite-Horizon Model," International Economic Review 33(4): 895919.

Chamley, Christophe. 1986. "Optimal Taxation of Capital Income in General Equilibrium with Infinite Lives," Econometrica 54(3): 607-622.

Chari, V.V., and Kehoe, Patrick J. 1990. "Sustainable Plans," Journal of Political Economy 98(4): 783-802.

Chari, V.V., and Kehoe, Patrick J. 1993. "Sustainable Plans and Mutual Default," Review of Economic Studies 60(1): 175-195.

Cole, Harold L., and Kehoe, Patrick J. 1997. "Models of Sovereign Debt: Practical vs. General Reputations," International Economic Review, forthcoming.

Cole, Harold L., and Kehoe, Timothy J. 1996. "A Self-Fulfilling Model of Mexico's 19941995 Debt Crisis," Journal of International Economics 41(3/4): 309-330.

Detragiache, Enrica. 1996. "Rational Liquidity Crises in the Sovereign Debt Market: In Search of a Theory," IMF Staff Papers, 43(3): 545-570.

Giavazzi, Francesco, and Pagano, Marco. 1990. "Confidence Crises and Public Debt Management," in Public Debt Management: Theory and History, ed. Rudiger Dornbusch and Mario Draghi, Cambridge University Press, Cambridge, 125-143.

International Monetary Fund. 1995. International Capital Markets: Developments, Prospects, and Policy Issues, International Monetary Fund, Washington, D.C. 
Kehoe, Timothy J. 1996. "Comments on 'Are Currency Crises Self-Fulfilling?' by Paul Krugman," in NBER Macroeconomics Annual 1996, ed. Ben S. Bernanke and Julio J. Rotemberg, MIT Press, Cambridge, MA, 378-392.

Krugman, Paul. 1996. "Are Currency Crises Self-Fulfilling?" in NBER Macroeconomics Annual 1996, ed. Ben S. Bernanke and Julio J. Rotemberg, MIT Press, Cambridge, MA, 345-378.

Lucas, Robert E. Jr., and Nancy L. Stokey. 1983. "Optimal Fiscal and Monetary Policy in an Economy without Capital," Journal of Monetary Economics 12(1): 55-93.

Missale, Alessandro, and Blanchard, Olivier Jean. 1994. "The Debt Burden and Debt Maturity," American Economic Review 84(1): 309-319.

Obstfeld, Maurice. 1994. "The Logic of Currency Crises," Cashiers Economiques et Monetaives (Bank of France) 43, 189-213.

Obstfeld, Maurice, and Rogoff, Kenneth. 1996. Foundations of International Macroeconomics, MIT Press, Cambridge, MA.

Sachs, Jeffery; Tornell, Aaron; and Velasco, Andres. 1996. "The Mexican Peso Crisis: Sudden Death or Death Foretold?" Journal of International Economics 41(3/4): 265283.

Stokey, Nancy L. 1991. "Credible Public Policy," Journal of Economic Dynamics and Control 15(4), 627-656. 


\section{Appendix}

\section{A1. Proof of Proposition}

We first consider the case where the participation constraint does not bind in period 0 or period 1 . We argue that in this case the equilibrium is stationary after period 1. Consequently, if the participation constraint does not bind in period 1, it does not bind afterward.

To determine optimal government behavior when the participation constraint does not bind, we can solve variational problem (10) to show that $g_{t}=g_{t+1}$.

We can now characterize equilibrium outcomes when the participation constraint does not bind: The initial capital stock is given by $K_{0}$, but is thereafter set at $k^{n}$. Consumption is determined by the capital stock according to the function $c^{n}(k)$. Government consumption is constant at

$$
g^{n}\left(B_{0}, K_{0}\right)=\theta f\left(K_{0}\right)-(1-\beta) B_{0}+\beta \theta\left(f\left(k^{n}\right)-f\left(K_{0}\right)\right),
$$

and government debt becomes constant after one period at

$$
B^{n}\left(B_{0}, K_{0}\right)=B_{0}+\theta\left(f\left(k^{n}\right)-f\left(K_{0}\right)\right) .
$$

The government's payoff from not defaulting in period 0 is

$$
\begin{aligned}
V_{g}^{n}\left(s_{0}, B^{n}\left(B_{0}, K_{0}\right), \beta\right)= & c^{n}\left(K_{0}\right)+v\left(g^{n}\left(B_{0}, K_{0}\right)\right) \\
& +\beta\left[c^{n}\left(k^{n}\right)+v\left(g^{n}\left(B_{0}, K_{0}\right)\right)\right] /(1-\beta)
\end{aligned}
$$

where $s_{0}=\left(B_{0}, K_{0}, 1, \cdot\right)$. Thereafter it is

$$
V_{g}^{n}\left(s, B^{n}\left(K_{0}, B_{0}\right), \beta\right)=\left[c^{n}\left(k^{n}\right)+v\left(g^{n}\left(K_{0}, B_{0}\right)\right)\right] /(1-\beta)
$$

where $s=\left(B^{n}\left(B_{0}, K_{0}\right), k^{n}, 1, \cdot\right)$. If both of these payoffs satisfy the participation constraint, then this is the equilibrium outcome.

When the participation constraint is violated in the proposed equilibrium described above, there are two possibilities: either the government can choose to default, or it can sell less new debt to reduce its incentive to default and thereby to satisfy the participation constraint.

To show that the participation constraint binds for at most two periods, we consider the case where $K=k^{n}$ since we know that $K_{1}=k^{n}$ if the government never defaults. We argue that there is a unique $B^{s}>0$ such that the stationary debt sequence $B^{s}$ satisfies the participation constraint with equality and that any stationary debt sequence $B<B^{s}$ satisfies the participation constraint strictly. Furthermore, if $B_{1}>B^{s}$ satisfies the participation constraint, then $B_{2}<B^{s}$. Consequently, once $K=k^{n}$, it takes at most one period for the government to adopt the stationary debt policy described previously.

To show that there is a unique $B^{s}>0$ such that $B_{1}=B_{2}=B^{s}$ satisfies the participation constraint with equality, let us write this constraint as $\left(V_{g}^{n}-V_{g}^{d}\right)\left(B_{1}, B_{2}\right) \geq 0$ where

$$
\begin{aligned}
\left(V_{g}^{n}-V_{g}^{d}\right)\left(B_{1}, B_{2}\right)= & c^{n}\left(k^{n}\right)+v\left(\theta f\left(k^{n}\right)-B_{1}+\beta B_{2}\right) \\
& +\beta\left[c^{n}\left(k^{n}\right)+v\left(\theta f\left(k^{n}\right)-(1-\beta) B_{2}\right)\right] /(1-\beta) \\
& -c^{d}\left(k^{n}\right)-v\left(\theta \alpha f\left(k^{d}\right)+\beta B_{2}\right) \\
& +\beta\left[c^{d}\left(k^{d}\right)+v\left(\theta \alpha f\left(k^{d}\right)\right] /(1-\beta) .\right.
\end{aligned}
$$

Notice that $\left(V_{g}^{n}-V_{g}^{d}\right)(0,0)>0$ and that $\left(V_{g}^{n}-V_{g}^{d}\right)(B, B) \rightarrow-\infty$ as $B \rightarrow \theta f\left(k^{n}\right) /(1-\beta)$. Furthermore, differentiating $V_{g}^{n}-V_{g}^{d}$ yields

$$
\frac{\partial}{\partial B_{1}}\left(V_{g}^{n}-V_{g}^{d}\right)(B, B)+\frac{\partial}{\partial B_{2}}\left(V_{g}^{n}-V_{g}^{d}\right)(B, B)<0 .
$$


Consequently, since $\left(V_{g}^{n}-V_{g}^{d}\right)$ is continuous in $\left(B_{1}, B_{2}\right)$, there is a unique $B^{s}, 0<B^{s}<$ $\theta f\left(k^{n}\right) /(1-\beta)$, such that $\left(V_{g}^{n}-V_{g}^{d}\right)\left(B^{s}, B^{s}\right)=0$ and $\left(V_{g}^{n}-V_{g}^{d}\right)(B, B)<0$ for all $B<B^{s}$, while $\left(V_{g}^{n}-V_{g}^{d}\right)(B, B)>0$ for all $B>B^{s}$.

To show that, if the government does not default and, if $B_{1}>B^{s}$, then $B_{2}<B^{s}$, we differentiate $V_{g}^{n}-V_{g}^{d}$ with respect to $B_{1}$ and $B_{2}$ separately. Since

$$
\frac{\partial}{\partial B_{2}}\left(V_{g}^{n}-V_{g}^{d}\right)\left(B_{1}, B_{2}\right)<0
$$

for all $B_{2} \geq B_{1}$, if $B_{2}=B_{1}$ violates the participation constraints, that is, if $\left(V_{g}^{n}-V_{g}^{d}\right)\left(B_{1}, B_{2}\right)<$ 0 , then the government cannot satisfy this constraint by trying to sell even more new debt $B_{2}$. Instead, the government can try to sell less new debt, and $B_{2}<B_{1}$ if any $B_{2}$ that satisfies the participation constraint exists. To see this, we apply the implicit function theorem to $\left(V_{g}^{n}-V_{g}^{d}\right)\left(B_{1}, B_{2}\right)=0$ at $B_{1}=B_{2}=B^{s}$ to calculate $d B_{2}\left(B_{1}\right) / d B_{1}$ :

$$
\frac{d}{d B_{1}} B_{2}\left(B^{s}\right)=-\frac{\partial}{\partial B_{1}}\left(V_{g}^{n}-V_{g}^{d}\right)\left(B^{s}, B^{s}\right) / \frac{\partial}{\partial B_{2}}\left(V_{g}^{n}-V_{g}^{d}\right)\left(B^{s}, B^{s}\right)<0 .
$$

This says that setting $B_{1}$ above $B^{s}$ requires us to decrease $B_{2}$ below $B^{s}$ to satisfy the participation constraint. For $B_{1}$ high enough, however, there is no value of $B_{2}$ for which the government satisfies the participation constraints and it is optimal to default.

We now argue that there is a continuous increasing function $\bar{B}\left(K_{0}\right)$ such that for all $B_{0} \leq \bar{B}\left(K_{0}\right)$, it is optimal for the government to never default, and for all $B_{0}>\bar{B}\left(K_{0}\right)$, it is optimal for the government to default in period 0 . We need to consider both the participation constraint in period 1 (A1) and that in period $0,\left(V_{g}^{n}-V_{g}^{d}\right)\left(B_{0}, B_{1}, B_{2}, K_{0}\right) \geq 0$ where

$$
\begin{aligned}
\left(V_{g}^{n}-V_{g}^{d}\right)\left(B_{0}, B_{1}, B_{2}, K_{0}\right)= & c^{n}\left(K_{0}\right)+v\left(\theta f\left(K_{0}\right)-B_{0}+\beta B_{1}\right) \\
& +\beta\left[c^{n}\left(k^{n}\right)+v\left(\theta f\left(k^{n}\right)-B_{1}+\beta B_{2}\right)\right. \\
& +\beta^{2}\left[c^{n}\left(k^{n}\right)+v\left(\theta f\left(k^{n}\right)-(1-\beta) B_{2}\right)\right] /(1-\beta) \\
& -c^{d}\left(K_{0}\right)-v\left(\theta \alpha f\left(K_{0}\right)+\beta B_{1}\right) \\
& -\beta\left[c^{d}\left(k^{d}\right)+v\left(\theta \alpha f\left(k^{d}\right)\right)\right] /(1-\beta) .
\end{aligned}
$$

We first argue that there is a continuous function $B_{1}\left(B_{2}\right)$ such that the participation constraint in period 1 is satisfied with equality. A similar argument implies that there is a continuous function $B_{0}\left(B_{1}, B_{2}, K_{0}\right)$ such that the participation constraint in period 0 is satisfied with equality. We then let

$$
\begin{aligned}
\bar{B}\left(K_{0}\right)= & \max B_{0}\left(B_{1}, B_{2}, K_{0}\right) \\
& \text { subject to } \\
& 0 \leq B_{1} \leq B_{1}\left(B_{2}\right) \\
& 0 \leq B_{2} \leq B^{s} .
\end{aligned}
$$

The constraint $B_{1} \leq B_{1}\left(B_{2}\right)$ binds if and only if the participation constraint binds in period 1 when $B_{0}=\bar{B}\left(K_{0}\right)$.

Differentiating $V_{g}^{n}-V_{d}^{n}$ in (A1), we obtain

$$
\frac{\partial}{\partial B_{1}}\left(V_{g}^{n}-V_{g}^{d}\right)\left(B_{1}, B_{2}\right)<0 \text {. }
$$


Furthermore, $\left(V_{g}^{n}-V_{g}^{d}\right)\left(0, B_{2}\right)>0$ and $\left(V_{g}^{n}-V_{g}^{d}\right)\left(B_{1}, B_{2}\right) \rightarrow-\infty$ as $B_{1} \rightarrow \theta f\left(k^{n}\right)+\beta B_{2}$. Consequently, for any $B_{2}$ there is a unique $B_{1}\left(B_{2}\right)$ for which the participation constraint holds with equality and $\left(V_{g}^{n}-V_{g}^{d}\right)\left(B_{1}, B_{2}\right)>0$ for all $B_{1}<B_{1}\left(B_{2}\right)$ and $\left(V_{g}^{n}-V_{g}^{d}\right)\left(B_{1}, B_{2}\right)<0$ for all $B_{1}>B_{1}\left(B_{2}\right)$. Since $\left(V_{g}^{n}-V_{g}^{d}\right) / \partial B_{1} \neq 0$, the implicit function theorem implies that $B_{1}\left(B_{2}\right)$ is continuous (in fact, continuously differentiable).

We now repeat the same argument for the function $V_{g}^{n}-V_{d}^{n}$ in (A2): Since

$$
\frac{\partial}{\partial B_{0}}\left(V_{g}^{n}-V_{d}^{g}\right)\left(B_{0}, B_{1}, B_{2}, K_{0}\right)<0
$$

and $\left(V_{g}^{n}-V_{g}^{d}\right)\left(0, B_{1}, B_{2}, K_{0}\right)>0$, while $\left(V_{g}^{n}-V_{g}^{d}\right)\left(B_{0}, B_{1}, B_{2}, K_{0}\right) \rightarrow-\infty$ as $B_{0} \rightarrow \theta f\left(K_{0}\right)+$ $\beta B_{1}$, there is a continuous function $B_{0}\left(B_{1}, B_{2}, K_{0}\right)$ for which the participation constraint in period 0 is satisfied with equality. Furthermore, we can use the implicit function theorem to show that $B_{0}\left(B_{1}, B_{2}, K_{0}\right)$ is increasing in $K_{0}$ :

$$
\frac{\partial}{\partial K_{0}} B_{0}\left(B_{1}, B_{2}, K_{0}\right)=\frac{-\frac{\partial}{\partial K_{0}}\left(V_{g}^{n}-V_{g}^{d}\right)\left(B_{0}, B_{1}, B_{2}, K_{0}\right)}{\frac{\partial}{\partial B_{0}}\left(V_{g}^{n}-V_{g}^{d}\right)\left(B_{0}, B_{1}, B_{2}, K_{0}\right)}>0
$$

for all $\left(B_{0}, B_{1}, B_{2}, K_{0}\right)$ such that $\left(V_{g}^{n}-V_{g}^{d}\right)\left(B_{0}, B_{1}, B_{2}, K_{0}\right)=0$.

Consider now the problem (A3). Since $B_{0}\left(B_{1} B_{2}, K_{0}\right)$ is continuous in $\left(B_{1}, B_{2}\right)$, it achieves a maximum on the compact constraint set. Furthermore, since $B_{0}\left(B_{1}, B_{2}, K_{0}\right)$ is also jointly continuous in $\left(B_{1}, B_{2}\right)$ and $K_{0}$, this maximum varies continuously with $K_{0}$.

Showing that $\bar{B}\left(K_{0}\right)$ is increasing in $K_{0}$ would seem to be a simple matter of applying the implicit function theorem. Unfortunately, unless we are willing to make assumptions on the second derivatives of $v$ like nonincreasing absolute risk aversion, we cannot ensure that the $\left(B_{1}, B_{2}\right)$ that solve $(\mathrm{A} 3)$ vary continuously with $K_{0}$. Suppose, however, that $B_{0}\left(B_{1}, B_{2}, K_{0}\right)=$ $\bar{B}\left(K_{0}\right)$ and that $\tilde{K}_{0}>K_{0}$. Fixing $\left(B_{1}, B_{2}\right)$, we know that $B_{0}\left(B_{1}, B_{2}, \tilde{K}_{0}\right)>\bar{B}\left(K_{0}\right)$. Consequently, as we allow $\left(B_{1}, B_{2}\right)$ to vary, we know that $\bar{B}\left(\tilde{K}_{0}\right) \geq B_{0}\left(B_{1}, B_{2}, \tilde{K}_{0}\right)>\bar{B}\left(K_{0}\right)$.

\section{A2. Proof of Proposition}

First fix $\gamma$ and let $\beta$ vary. Notice that, as $\beta \rightarrow 1, \bar{W}(\beta) \rightarrow-\infty$. Consider the level of debt $B(\beta)$ such that

$$
W_{n l}(B(\beta))=\bar{W}(\beta) .
$$

As $\beta \rightarrow 1, B(\beta) \rightarrow \theta f\left(k^{n}\right)$ and $W_{p}(B(\beta)) \rightarrow \infty$. Consequently,

$$
W_{p}(B(\beta))>\bar{W} \geq W_{n l}(B(\beta)) .
$$

Hence, for a fixed $\beta<1$ for which this inequality is satisfied, there is a nonempty interval of debt levels $B>B(\beta)$ in the crisis zone.

Now fix $\beta$ and let $\gamma$ vary. Since $\gamma>0$, we can divide $W_{p}, W_{n l}$, and $\bar{W}$ by $\gamma$. Note that $W_{p} / \gamma$ and $W_{n l} / \gamma$ are independent of $\gamma$, while $\bar{W} / \gamma$ can be made arbitrarily negative (since $\bar{W}<0)$ as $\gamma$ goes to zero. Since $W_{n l}$ tends to $-\infty$ for a lower value of $B$ than does $W_{p}$, by choosing $\gamma$ sufficient close to zero, we can ensure that a nonempty crisis zone exists. (See Figure 1.) 


\section{A3. Proof of Proposition}

Consider varying $\alpha$ and letting $B(\alpha)$ be such that

$$
W_{p}(B(\alpha))=\bar{W}(\alpha) .
$$

In the extreme case, as $\alpha \rightarrow 0$,we know that $B(\alpha) \rightarrow f\left(k^{n}\right) /(1-\beta)$. Consequently, for $\alpha$ sufficiently small, $B(\alpha)>f\left(k^{n}\right)$ and $W_{n l}(B(\alpha))=-\infty$. This implies that

$$
W_{p}(B(\alpha))=\bar{W}(\alpha)>W_{n l}(B(\alpha)) .
$$

\section{A4. Proof of Proposition}

If, in the event of a crisis, the government chooses not to default, then the worst possible outcome will be for it to have to repay all of the debt coming due each period. In this case, the no-lending condition becomes

$$
\begin{aligned}
& \left(1-\beta^{N}\right)\left[c^{n}\left(k^{n}\right)+v\left(\theta f\left(k^{n}\right)-B_{N}\right)\right] /(1-\beta)+\beta^{N}\left[c^{n}\left(k^{n}\right)+v\left(\theta f\left(k^{n}\right)\right)\right] /(1-\beta) \geq \\
& c^{d}\left(k^{n}\right)+v\left(\theta \alpha f\left(k^{n}\right)\right)+\beta\left[c^{d}\left(k^{d}\right)+v\left(\theta \alpha f\left(k^{d}\right)\right)\right] /(1-\beta) .
\end{aligned}
$$

Recall that, with one period bonds, the maximum stationary debt level $B^{s}$ is characterized by the equation

$$
\begin{aligned}
& {\left[c^{n}\left(k^{n}\right)+v\left(\theta f\left(k^{n}\right)-(1-\beta) B^{s}\right)\right] /(1-\beta)=} \\
& c^{d}\left(k^{n}\right)+v\left(\theta \alpha f\left(k^{n}\right)+\beta B^{s}\right)+\beta\left[c^{d}\left(k^{d}\right)+v\left(\theta \alpha f\left(k^{d}\right)\right)\right] /(1-\beta) .
\end{aligned}
$$

Notice that, as $N \rightarrow \infty, B_{N} \rightarrow 0$ and $B_{N} \rightarrow(1-\beta) B$. Consequently, as $N \rightarrow \infty$, the left-hand side of (A5) tends to

$$
\left[c^{n}\left(k^{n}\right)+v\left(\theta f\left(k^{n}\right)-(1-\beta) B\right)\right] /(1-\beta)
$$

which is greater than or equal to the left-hand side of (A6) for all $B$ in the interval $\bar{b}\left(k^{n}\right)<$ $B \leq B^{s}$. The right-hand side of (A5) is always strictly less than the right-hand side of (A6), however. Consequently, there exists a finite maturity level $N^{\prime}$ such that, for all maturity levels $N \geq N^{\prime}$, (A5) is satisfied for all $B$ in the interval $\bar{b}\left(k^{n}\right)<B \leq B^{s}$.

\section{A5. Proof of Proposition}

If the government prefers not defaulting to defaulting, conditional on keeping a constant debt level, then it certainly does so under the optimal debt policy; hence, $B^{s}(\pi) \leq$ $\bar{B}\left(k^{\pi}, \pi\right)$. As $\pi$ increases, however, we can use the implicit function theorem to show that $B^{s}(\pi)$ decreases, making it more difficult for a nonempty interval $\bar{b}\left(k^{n}\right)<B \leq B^{s}(\pi)$ to exist. To show (i), notice that $B^{s}(0)>\bar{b}\left(k^{n}\right)$ implies that, if $K_{0}=k^{n}$ and $B_{0}=B_{1}=\bar{b}\left(k^{n}\right)$, then the participation constraint with $q=\beta$ and $K_{1}=k^{n}$ is strictly satisfied, and hence it is also satisfied by $B_{0}$ slightly larger than $\bar{b}\left(k^{n}\right)$. Since this holds for any $\pi, \bar{B}\left(k^{n}, \pi\right)>\bar{b}\left(k^{n}\right)$. To show (ii), notice that $B^{s}(0)>\bar{b}\left(k^{n}\right)$ implies that $B^{s}(\pi)>\bar{b}\left(k^{n}\right)$ for $\pi$ close to 0 from the continuity of the functions in (15).

\section{A6. Proof of Proposition}

Consider first the case where $K_{0}=k^{\pi}$. Either the maximum of $V_{g}^{T}\left(B_{0}\right)$ is achieved for some finite $T$ or it is not. If it is not, then

$$
V_{g}^{\infty}\left(B_{0}\right)=\lim _{T \rightarrow \infty} V_{g}^{T}\left(B_{0}\right)>V_{g}^{T}\left(B_{0}\right)
$$


for all finite $T$, and never running down the debt is optimal. (Notice that $B_{0} \leq B^{s}(\pi)$ implies that at the optimal $T, V_{g}^{T}\left(B_{0}\right) \geq V_{g}^{d}\left(B_{0}\right)$.)

We now argue that as $B_{0}$ increases above $\bar{b}\left(k^{n}\right)$, it can pass through critical points where the optimal $T$ increases by one period. For $\bar{b}\left(k^{n}\right)<B_{0} \leq \bar{b}\left(k^{n}\right) /(1-\pi)$, it is optimal to set $T=1$, because the yield from selling $\bar{b}\left(k^{n}\right), \beta \bar{b}\left(k^{n}\right)$, is greater than $\hat{\beta} B_{1}$ for any $\bar{b}\left(k^{n}\right)<B_{1}<B_{0}$. As we increase $B_{0}$, we can pass through a critical point where the optimal $T$ increases to $T=2$. It cannot increase by more, because the optimal government policy is to steadily decrease $B$ if it is to decrease at all. Therefore, there must be a region of values of $B_{0}$ where it is optimal to set $T=2$ in between the regions where it is optimal to set $T=1$ and where it is optimal to set $T=3$. As we increase $B_{0}$ even further, we can increase $T$, but we can never decrease it. To see why the optimal $T$ can never decrease, observe that for $\bar{b}\left(k^{n}\right)<B_{0}<\bar{b}\left(k^{n}\right) /(1-\pi)$,

$$
V_{g}^{1}\left(B_{0}\right)>V_{g}^{2}\left(B_{0}\right)>\ldots>V_{g}^{\infty}\left(B_{0}\right) .
$$

By setting $T=1$ for $B_{0}$ in this region, the government can avoid crises without sacrificing government spending, and every period that it delays is costly. Differentiating our formula for $V_{g}^{T}\left(B_{0}\right)$, we obtain

$$
0>\frac{d}{d B_{0}} V_{g}^{\infty}\left(B_{0}\right)>\ldots>\frac{d}{d B_{0}} V_{g}^{2}\left(B_{0}\right)>\frac{d}{d B_{0}} V_{g}^{1}\left(B_{0}\right) .
$$

Therefore, if $V^{T}(B) \leq V^{T^{*}}(B)$ for $T^{*}>T$, then for any $B^{*}>B, V^{T}\left(B^{*}\right)<V^{T^{*}}\left(B^{*}\right)$. Hence, if it is optimal to reduce the debt from $B_{0}$ to $\bar{b}\left(k^{n}\right)$ in $T$ periods, then for higher $B_{0}$, it cannot be optimal to reduce the debt in $T-1$ periods.

As $\pi$ tends to 0 , the equilibria tend to those of the zero-probability crisis equilibria. For $\pi$ close enough to 0 , it is easy to show that there are necessarily regions of $B_{0}$ with the full range of possibilities $T=1,2, \ldots, \infty$. Let $V_{g}\left(B_{0}, T\right)=V_{g}^{T}\left(B_{0}\right)$ and $g\left(B_{0}, T\right)=g^{T}\left(B_{0}\right)$, where we think of $T$ as a continuous variable. We can differentiate our formula for $V_{g}^{T}$ with respect to $T$. If we can find that for fixed $B_{0}>\bar{b}\left(k^{n}\right)$ and for $\pi$ small enough, $\partial V_{g}\left(B_{0}, T\right) / \partial T>0$ for all $T$, then we know that even for discrete $T$, increasing $T$ yields a higher expected payoff for the government. Differentiating $V_{g}\left(B_{0}, T\right)$, we obtain

$$
\begin{aligned}
\frac{\partial}{\partial T} V_{g}\left(B_{0}, T\right)= & \hat{\beta}^{T-1}\left\{(1-\pi)(\log \hat{\beta}) v^{\prime}\left(g\left(B_{0}, T\right)\right)\left(\beta \bar{b}\left(k^{n}\right)-\hat{\beta} B_{0}\right) /\left(1-\hat{\beta}^{T}\right)^{2}\right. \\
& -(\log \hat{\beta})\left[(1-\pi)\left(c^{\pi}\left(k^{\pi}\right)+v\left(g\left(B_{0}, T\right)\right)\right)+\pi V_{g}^{d}\right] /(1-\hat{\beta}) \\
& +(\log \hat{\beta})\left[(1-\pi)\left(c^{n}\left(k^{\pi}\right)+v\left(g\left(B_{0}, T\right)\right)\right)+\pi V_{g}^{d}\right] \\
& \left.+\hat{\beta}(\log \hat{\beta})\left[c^{n}\left(k^{n}\right)+v\left(\theta f\left(k^{n}\right)-(1-\beta) \bar{b}\left(k^{n}\right)\right)\right] /(1-\beta)\right\} .
\end{aligned}
$$

Fortunately, this formula is easy to interpret. As $T$ tends to $\infty, \partial V_{g}\left(B_{0}, T\right) / \partial T$ tends to 0 , because $V_{g}\left(B_{0}, T\right)$ tends to $V_{g}^{\infty}\left(B_{0}\right)$. Even so, we are concerned with the sign of $\partial V_{g}\left(B_{0}, T\right) / \partial T$. The benefit of increasing $T$ is that the government can maintain a higher level of government spending, and this benefit is captured by the first term in the formula above. Notice that as $\pi$ tends to 0 , this benefit remains positive once we factor out $\hat{\beta}^{T-1}$. The cost of increasing $T$ is that the government risks crises for more periods, and this cost is captured by the last three terms in the formula above. Notice that as $\pi$ tends to 0 , this cost goes to zero, even after we factor out $\hat{\beta}^{T-1}$.

Now fix a $B_{0}>\bar{b}\left(k^{n}\right)$ and a $\pi$ for which $\partial V_{g}\left(B_{0}, T\right) / \partial T>0$ for all $T$. The optimal government policy is to set spending equal to $g^{\infty}\left(B_{0}\right)$ and maintain debt at $B_{0}$. Our previous 
arguments now imply that for any $T$, there exists some initial $B, \bar{b}\left(k^{n}\right)<B<B_{0}$, for which the optimal government policy is to run its debt down to $\bar{b}\left(k^{n}\right)$ in $T$ periods. We know that for $\bar{b}\left(k^{n}\right)<B \leq \bar{b}\left(k^{n}\right) /(1-\pi)$, it is optimal to run down the debt in one period. We also know that for $B=B_{0}>\bar{b}\left(k^{n}\right) /(1-\pi)$, it is optimal to never run down the debt. Somewhere between $\bar{b}\left(k^{n}\right) /(1-\pi)$ and $B_{0}$, all other intermediate possibilities must exist.

To rule out the possibility of there being a sudden jump from a finite $T$ being optimal to it being optimal to maintain the debt level constant, suppose to the contrary, that such a jump does occur. Then, at the debt level $B$ where this jump occurs, we know that $V_{g}^{T}(B)=V_{g}^{\infty}(B)$, but $V_{g}^{T *}(B)<V_{g}^{T}(B)$ for all $T^{*}>T$. Furthermore, $V_{g}^{\infty}\left(B^{*}\right)>V_{g}^{T}\left(B^{*}\right)$ for all $B^{*}>B$. The continuity of $V_{g}^{T}$ and $V_{g}^{T+1}$ implies that we can choose $\tilde{B}>B$ so that $V_{g}^{T}(\tilde{B})>V_{g}^{T+1}(\tilde{B})$. Since

$$
0>\frac{d}{d B} V_{g}^{T+1}(B)>\frac{d}{d B} V_{g}^{T}(B)
$$

$V_{g}^{T}(B)>V_{g}^{T+1}(B)$ for all $B \leq \tilde{B}$. Since $V_{g}^{T}(\tilde{B}) \rightarrow V_{g}^{\infty}(\tilde{B})$ as $T \rightarrow \infty$, however, we know that there exists a $\tilde{T}>T+1$ sufficiently large so that $V_{g}^{\tilde{T}}(\tilde{B})>V_{g}^{T}(\tilde{B})$. Consequently, if we restrict the government's choices to the set $1,2, \ldots, \tilde{T}$, we know that at $B_{0}=\tilde{B}$ it would choose to run down its debt in $\tilde{T}$ periods. Our previous arguments now imply that there has to be a region where $B<\tilde{B}$ and where it is optimal to run down the debt in $T+1$ periods, in particular where $V_{g}^{T+1}(B)>V_{g}^{T}(B)$. This contradiction rules out the possibility of a sudden jump.

For the case when $K_{0} \neq k^{\pi}$, a similar variational argument implies that under the optimal policy, $g$ is constant during the transition to $\bar{b}\left(k^{n}\right)$. Furthermore, if instead of $\left(K_{0}, B_{0}\right)$ as its state, the government has $\left(k^{\pi}, B_{0}+\theta\left(f\left(k^{\pi}\right)-f\left(K_{0}\right)\right)\right.$, where $B_{0}+\theta\left(f\left(k^{\pi}\right)-f\left(K_{0}\right) \leq B^{s}(\pi)\right.$ so that the participation constraint does not bind, the government's problem is unchanged, except that private consumption is different in period 0 . Hence, the solution is unchanged. Notice that $B_{1}$ is weakly less than $B_{1}+\theta\left(f\left(k^{\pi}\right)-f\left(K_{0}\right)\right.$, but this does not imply that $B_{1} \leq B_{0}$ if $K_{0}<k^{\pi}$.

\section{A7. Proof of Proposition}

The characterization of the crisis equilibrium works similarly to that of the no-crisis equilibrium in Proposition 1. In the no-crisis equilibrium, the stationary debt policy characterizes optimal government behavior and, implicitly, equilibrium outcomes when the participation constraint does not bind. In the crisis equilibrium, $T\left(B_{0}\right)$ and $V_{g}^{T}\left(B_{0}\right)$ characterize optimal government behavior and, implicitly, equilibrium outcomes when the participation constraint does not bind.

When the participation constraint does bind, we can use the identical logic as that in the proof of Proposition 1 to argue that, if $K=k^{\pi}$ then, the equilibrium adjusts to that characterized by $T(B)$ and $V_{g}^{T}(B)$ in at most one period; in particular, if $B_{1}>B^{s}(\pi)$, then $B_{2}<B^{s}(\pi)$ and the government runs down its debt in $T\left(B_{2}\right)$ periods starting in the period after $K=k^{\pi}$. If $K_{0}=k^{\pi}$, this is period 1 , but if $K_{0} \neq k^{\pi}$ and if the participation constraint binds in period 1 , it is period 2 . We need to also allow for the possibility that $K=k^{n}$ if the government needs to lower either $B_{1}$ or $B_{2}$ so much to satisfy the participation constraints in period 0 or period 1 so that $B_{1}$ or $B_{2}$ is less than or equal to $\bar{b}\left(k^{n}\right)$. Otherwise, the proof follows the identical logic as that of Proposition 1. The notation involved in writing out the expressions for $V_{g}^{n}-V_{g}^{n}$ analogous to those in (A1) and (A2) is straightforward, but tedious. We omit it here. 
Figure 1. SUNSPOT EQULIBRIA?

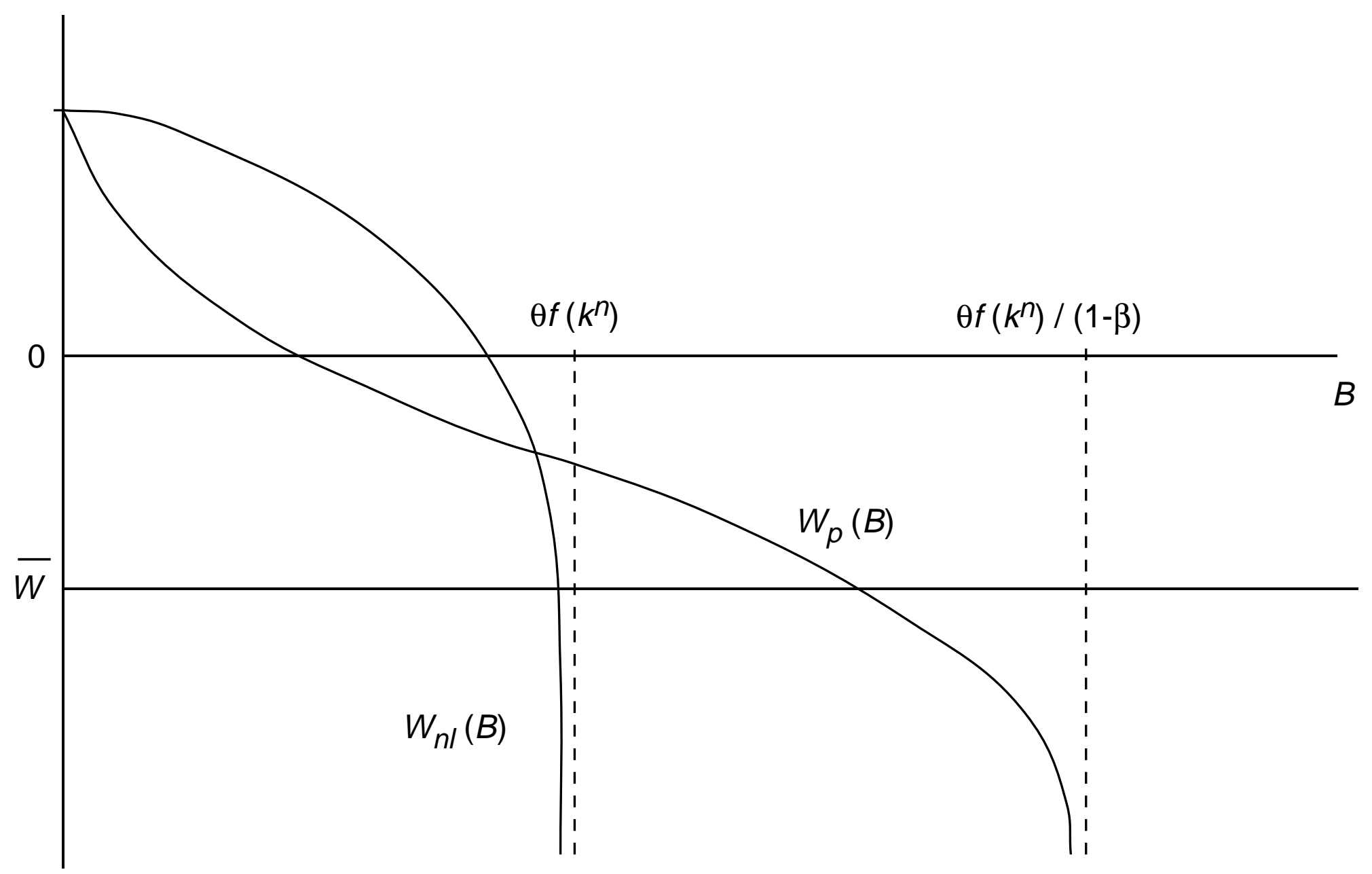


Figure 2. DEBT TRAJECTORIES IF A CRISIS IS AVOIDED

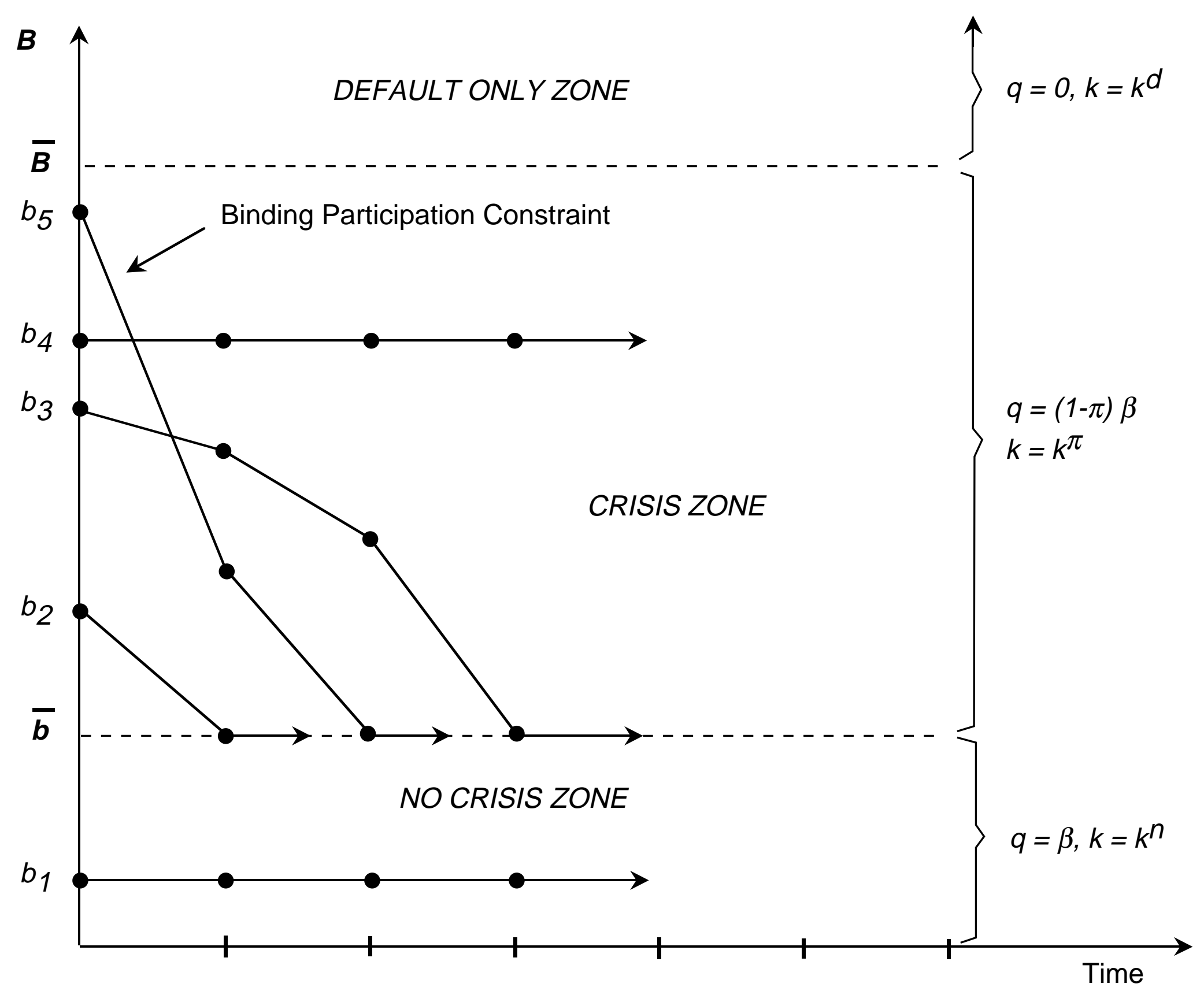

